Cite this: J. Mater. Chem. A, 2013, 1, 13379

Received 1st July 2013 Accepted 7th August 2013

DOI: 10.1039/c3ta12555f www.rsc.org/MaterialsA

\section{Progress in bio-based plastics and plasticizing modifications}

\begin{abstract}
Tizazu Mekonnen, ${ }^{a}$ Paolo Mussone, ${ }^{a}$ Hamdy Khalil ${ }^{b}$ and David Bressler*a
Over the coming few decades bioplastic materials are expected to complement and gradually replace some of the fossil oil based materials. Multidisciplinary research efforts have generated a significant level of technical and commercial success towards these bio-based materials. However, extensive application of these bio-based plastics is still challenged by one or more of their possible inherent limitations, such as poor processability, brittleness, hydrophilicity, poor moisture and gas barrier, inferior compatibility, poor electrical, thermal and physical properties. The incorporation of additives such as plasticizers into the biopolymers is a common practice to improve these inherent limitations. Generally, plasticizers are added to both synthetic and bio-based polymeric materials to impart flexibility, improve toughness, and lower the glass transition temperature. This review introduces the most common bio-based plastics and provides an overview of recent advances in the selection and use of plasticizers, and their effect on the performance of these materials. In addition to plasticizers, we also present a perspective of other emerging techniques of improving the overall performance of bio-based plastics. Although a wide variety of bio-based plastics are under development, this review focuses on plasticizers utilized for the most extensively studied bioplastics including poly(lactic acid), polyhydroxyalkanoates, thermoplastic starch, proteinaceous plastics and cellulose acetates. The ongoing challenge and future potentials of plasticizers for bio-based plastics are also discussed.
\end{abstract}

\section{Introduction}

Plastics are amorphous organic solid polymers covering a wide range of polymerization products suitable for the manufacture of diversified products. Worldwide annual plastics production is estimated to surpass 300 million tons by 2015 (ref. 1) representing trillions of dollars in terms of global economic returns. ${ }^{2}$

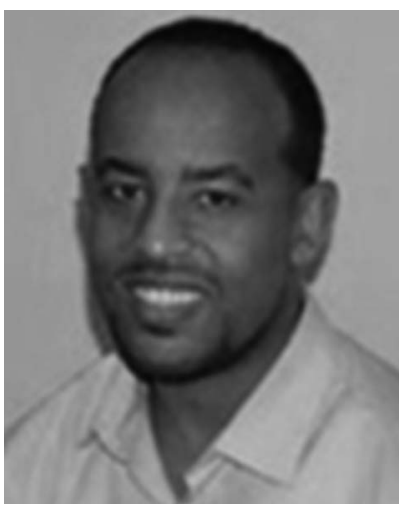

Tizazu Mekonnen earned his BSc degree in Applied Physics (2004) and MSc degree in Chemical Engineering (2009) from Addis Ababa University, Ethiopia. He is currently finalizing his PhD in Bioresource Engineering under the supervision of Professor David Bressler at the Biorefining Conversions and Fermentations Lab at the University of Alberta, Canada. Mr Mekonnen's PhD research work entails hydrolysis and biorefining of hazardous waste protein biomass to fabricate and study novel biopolymers and biopolymersynthetic polymer hybrid materials for various industrial applications.

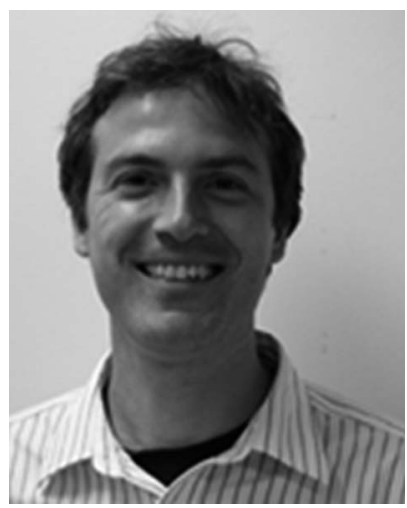

Dr Mussone holds a position as Research Associate with the Biorefining Conversions and Fermentations Laboratory at the University of Alberta. Dr Paolo Mussone earned an MSc degree in Process Engineering from the Polytechnic University of Milan in Italy and $a$ PhD in Surface Chemistry and Colloidal Science from the University of Manchester in the United Kingdom. Dr Mussone's general research focus is on the conversion of biomass into value-added chemicals and materials. Of particular interest is the development of renewable polymeric surfactant platforms for heavy petroleum processing and waste water treatment processes. 
Plastics are highly valued materials because of their low cost and extraordinary versatility and they constitute the largest petroleum application second only to energy. ${ }^{3}$ Among the many applications of plastics, packaging accounts for almost onethird of their use followed by construction and consumer products. ${ }^{4}$ The materials science community has been striving for decades to generate bio-based plastics to substitute or complement conventional synthetic plastics based on exclusively petroleum feedstock. According to current estimates, the global production of bioplastics is expected to grow at an annual rate of up to $30 \%$ in the coming decade to reach 3.5 million tonnes in $2020 .^{5}$

Bioplastics may also be bio-based (i.e. polymer derived from renewable feedstock) and biodegradable (i.e. polymer that can return to nature). ${ }^{6}$ Biodegradability and compostability depend on the chemical structure rather than the feedstock source. According to the US Department of Agriculture (USDA), biobased products are defined as commercial or industrial goods (other than feed or food) composed in whole or in significant part of biological products. ${ }^{7}$ Thus, synonymous use of the terms bio-based plastic and biodegradable plastic is not correct. Some of the most commonly known bio-based plastics in today's marketplace in terms of production and renewability are poly(lactic acid) (PLA), polyhydroxyalkanoates (PHAs), starch plastics, cellulose esters and protein based plastics (Fig. 1). Other bio-based plastics, such as bio enriched polyurethane manufactured using modified vegetable oils, polyethylene monomers derived from the dehydration of bio-ethanol, polypropylene monomers derived from dehydration of bio-butanol and poly(ethylene terephthalate) monomers produced via fermentation, catalytic pyrolysis or gasification of biomass, ${ }^{\mathbf{8}}$ that have at least partial sourcing from plants constitute emerging technologies expected to make a significant market impact.

Bio-based plastics could overcome the sustainability issues and environmental challenges posed by the production and disposal of synthetic plastics. However, the large scale commercial deployment of bio-based plastics to replace conventional plastic materials remains challenged by several factors. Some of the challenges are attributed to the relatively poor performance, variability of properties of the feedstock associated with location and the time of harvest, high production cost and lack of infrastructure. Recent development in bacteria synthesized plastics (PHAs) and the utilization of nature's own building blocks such as proteins, fats, carbohydrates, lignin, etc. obtained from agricultural feedstock and agricultural industry wastes constitute a major progress towards bio-based plastics in the last decade.

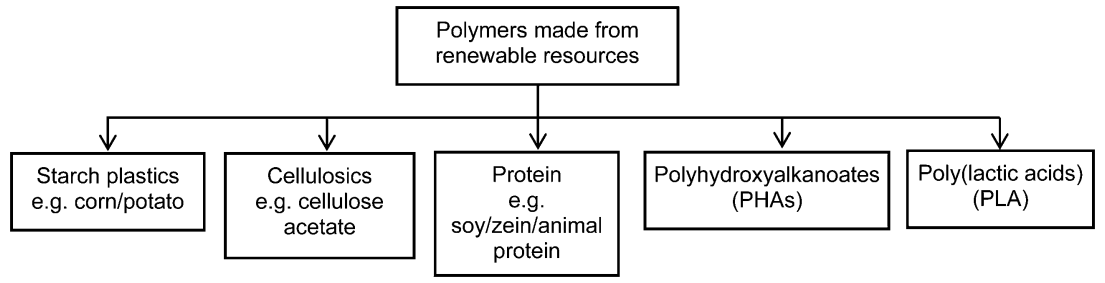

Fig. 1 Major bio-based plastics and their production routes. ${ }^{6}$

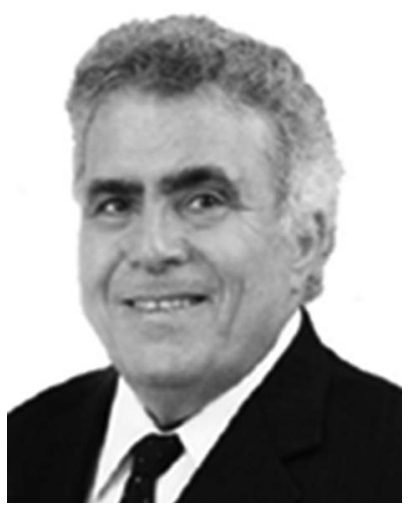

Dr Hamdy Khalil is the Senior Global Director for Advanced Technologies and Innovation. He pioneered the introduction of chemicals derived from renewable resources into the manufacturing of automotive parts and the application of Phase Transfer Catalysis in the synthesis of heterocyclic compounds. Dr Khalil is a member of the Board of Directors of several industrial organizations. He chaired and participated in many International Conferences related to Biotechnology as well as Polyurethane Technology. Dr Khalil is a member of the American Chemical Society and the Canadian Institute of Chemistry. He has several patents and publications in the areas of Bio-polyols, Sealants, Latex and Polystyrene.

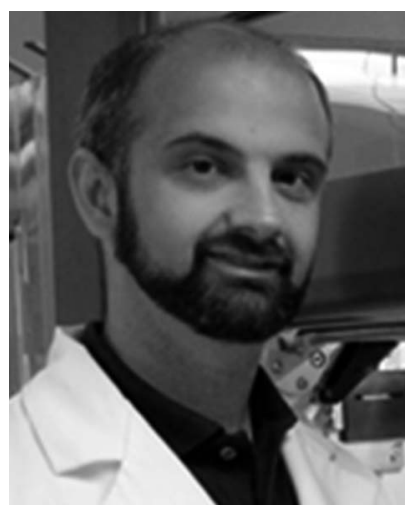

Dr Bressler is currently a tenured Professor in the Food and Bioresource Technology Division of the Faculty of Agricultural, Life, and Environmental Sciences at the University of Alberta. He is also Founding Director of the Biorefining Conversions Network, an organization focused on facilitating the development of novel, commercially viable biomass conversion technologies, and value-added products within Alberta, Canada. Dr Bressler's general area of research is the industrial application of chemical, thermal, and biological systems for the conversion of conventional agricultural products to platform chemicals and other value-added commodities. 
Plasticizers have long been known for their effectiveness in enhancing the flexibility of synthetic plastics such as polyvinyl chloride (PVC) and epoxy resins. New types of plasticizers compatible with bio-based plastics are being developed. For technical and economic reasons, polymer additives are a large and increasingly significant component of the polymer industry. ${ }^{9}$ Among the additives, plasticizers constitute about one third of the global additive market, ${ }^{\mathbf{1 0}}$ with a worldwide consumption of over 4.6 million metric tonnes in 2003 (ref. 11) and over 6.4 metric tonnes in 2011. ${ }^{12}$ Generally, plasticizers are small, relatively non-volatile, organic molecules that are added to polymers to reduce brittleness, impart flexibility, and improve toughness, reducing crystallinity, lowering glass transition and melting temperatures. ${ }^{\mathbf{1 3 , 1 4}}$ Plasticization reduces the relative number of polymer-polymer contacts thereby decreasing the rigidity of the three-dimensional structure thereby allowing deformation without rupture. ${ }^{15}$ Consequently, plasticizers improve processability, flexibility, durability and in some cases reduce the cost of polymers. ${ }^{16,17}$

The use of plasticized polymers in pharmaceutical applications ranging from packaging materials or auxiliary substances in conventional dosage forms to membranes or matrices modifying and controlling the drug release characteristics in therapeutic systems has been reported in the literature. ${ }^{\mathbf{1 6 , 1 8 , 1 9}}$ The processing behaviour, such as film formation and coating dispersion, and properties of polymers in various applications are greatly improved by adequate choice of plasticizer type and quantity. ${ }^{\mathbf{1 6 , 2 0}}$ Generally, the choice of these plasticizers to be used as modifiers of plastics is limited by the required safety, environmental favorability, chemical and physical property that dictate their miscibility, processing temperature and required flexibility towards the target application. ${ }^{17}$

The risk of leaching out of certain plasticizers, such as phthalates during storage or end-user application, constitutes a major safety risk. ${ }^{21-24}$ This coupled with other shortcomings (e.g. toxicity, poor compatibility) limits some plasticizers from application in the medical, pharmaceutical and food packaging fields. The ideal plasticizer significantly lowers the glass transition temperature $\left(T_{\mathrm{g}}\right)$, is biodegradable, nonvolatile, and nontoxic, and exhibits minimal leaching or migration during use or aging.

Recent advances in bio-based plastics are spurred by factors such as public concern over the depletion of petroleum based raw materials, the desire of manufacturing companies to develop more sustainable raw material sources, the improvement in properties as well as cost competitive relationship of bioplastics. ${ }^{25,26}$ As these bio-based plastic industries continuously grow, the demand for new types of plasticizers with new characteristics, performance and other additives that are compatible with the bioplastics also grows in the same direction. ${ }^{27}$ In the realm of developing packaging materials from biobased materials, a high ductility at room temperature is required and thus, there is no tolerance for the polymer film tearing or cracking when subjected to stresses during package manufacturing or use. ${ }^{28}$ Moreover, increase in the utilization of plasticized polymers for biomedical and pharmaceutical application, ${ }^{\mathbf{1 6}}$ the search for safer plasticizers for commodity plastics such as poly(vinyl chloride) ${ }^{29-31}$ and efforts to produce renewable and biodegradable plasticizers ${ }^{29,30}$ constitute an additional motive for the recent development of new plasticizers. This review briefly reports recent progress in the development of plasticizers utilized for bio-based plastics, and their influence on the performance of bio-based plastics.

\section{Plasticization mechanism}

Two types of plasticizers are defined in polymer science: internal and external..$^{2,23,32}$ Internal plasticizers are part of the polymer molecules, co-polymerized into the polymer structure, grafted or reacted with the original polymer thereby making the polymer chains more difficult to fit and compact with each other closely. ${ }^{23}$ They soften polymers by lowering the glass transition temperature $\left(T_{\mathrm{g}}\right)$ and reducing the elastic modulus. ${ }^{22}$ External plasticizers, on the other hand, are low volatility molecules added to interact with polymers and produce swelling without chemical reaction. Internal molecular forces between plasticizer molecules and between a plasticizer and a polymer such as dispersion forces, induction forces, dipoledipole interaction, hydrogen bonds are important in external plasticization. ${ }^{23}$

Several theories have been proposed to explain the mechanism and action of plasticizers on polymers. Among those theories, the following plasticizing mechanisms have been widely accepted to describe the effect of plasticizers on polymeric networks: ${ }^{33-36}$ (a) the lubricity theory: this theory is similar to metal parts lubrication by oil. The plasticizer acts as a lubricant to reduce friction and facilitates polymer chain mobility past one another, consequently lowering deformation; (b) the gel theory: this theory extends the lubricity theory and suggests that a plasticizer disrupts and replaces polymerpolymer interactions (hydrogen bonds, van der Waals or ionic forces, etc.) that hold polymer chains together resulting in reduction of the polymer gel structure and increased flexibility; and (c) the free volume theory: for any polymeric material the free volume is defined as the internal space available in a polymer for the movement of chains. Free volume is usually described as the difference between the observed volume at absolute zero and the volume measured at a selected temperature. Rigid resins are characterized by limited free volume whereas flexible resins have relatively large amounts of free volume. Plasticizers increase the free volume of resins and also maintain the free volume after the polymer-plasticizer mixture post processing is cooled down. The free volume theory explains the effect of plasticizers in lowering the glass transition temperature.

Although these theories are widely accepted and utilized in the selection of plasticizer for polymers, Shtarkman and Razinskaya ${ }^{35}$ stressed the limitation of the current plasticization theories. According to these authors, ${ }^{35}$ the plasticization theories are limited and not feasible for plasticizer selection for the following reasons: (1) direct studies of the plasticization mechanism is lacking and (2) the existing plasticization theories have limited predicting capability and are limited to only particular cases. For this purpose, the authors ${ }^{35}$ suggested the 
necessity of a compatibility-efficiency-property study that takes into account the structure of the polymeric system to select a specific plasticizer rather than relying on the theories.

The aforementioned plasticization theories/mechanisms were developed for synthetic plastics, particularly PVC. Limited attention has been devoted to developing new theories/mechanisms or improving established theories to explain the plasticization mechanism of the newly developed and emerging biobased plastics. The complex nature of some of the biological feedstock macromolecules makes bio-based plastics radically different from the common repeating monomer based synthetic polymers. Hence, renewed efforts are required to investigate other more explanatory plasticization possibilities and theories.

\section{Plasticization of bio-based plastics}

\subsection{Poly(lactic acid) plastics}

Poly(lactic acid) (PLA) is one of the most promising innovative plastics for various end-use applications. This polymer is thermoplastic, renewable, biodegradable and biocompatible, a set of highly attractive attributes for pharmaceutical, biological and medical applications. ${ }^{37,38}$ The raw material of PLA, L-lactic acid, can be produced by fermentation of renewable sugar resources such as starch and other polysaccharides. ${ }^{39,40}$ Moreover, PLA exhibits a remarkable balance of performance properties comparable to traditional thermoplastics ${ }^{39}$ processed using conventional plastic processing techniques. From a physical property standpoint it is often loosely compared to polystyrene. ${ }^{37}$ Similar to polystyrene, standard grade PLA has high modulus and strength. ${ }^{37,41}$ Moreover, the degradation products of polylactides are nontoxic which enhances practical applications in biomedicine. ${ }^{42}$ PLA is currently being commercialized for a wide spectrum of technologically important fields and applications by companies such as Cargill and Dow Chemicals. ${ }^{38}$

PLA belongs to the family of aliphatic polyesters commonly made from lactic acid (2-hydroxypropionic acid) building block shown in Fig. 3. The synthesis of lactic acid into high-molecular weight PLA can follow two different routes of polymerization, ${ }^{\mathbf{4 0 , 4 3}}$ as depicted in Fig. 4. The monomer lactic acid is condensation polymerized to yield a low-molecular weight, brittle, glassy polymer in the first route, which, for the most part, is unusable unless external coupling agents are used to increase the molecular weight of the polymer. ${ }^{40}$ The second route of producing PLA is to collect, purify, and ring-open and polymerize lactide to yield high molecular weight (average $M_{\mathrm{w}}>$ 100 000) PLA. ${ }^{40,43,44}$

The combination of the chiral lactic acid monomers (Fig. 2) or the depolymerization of low molecular weight PLA (Fig. 3) could give rise to distinct forms of polylactides. These polylactides are poly(L-lactide) (or LL-lactide), poly(D-lactide) (or DDlactide), poly(LD-lactide) (or meso-lactide) as shown in Fig. 4 or a mixture of L-and D-lactides, called racemic lactide (rac-lactide). ${ }^{38,46,47}$ While the $\mathrm{D}^{-}$and $\mathrm{L}$ - lactides are optically active, mesois not (Fig. 4). ${ }^{46}$ Highly crystalline PLA can be obtained with low D content $(<2 \%)$, fully amorphous PLA on the other hand can be obtained with high D content $(>20 \%) .{ }^{48}$ Semi-crystalline PLA is obtained with 2 to $20 \%$ of D content. ${ }^{2}$ The amount and stereosequence of these lactides in the polymer backbone give rise to a wide range of molecular weights. These changes as a result impact the melt behavior, thermal, mechanical, optical properties, barrier properties and biological properties of PLA. $^{49,50}$

PLA is brittle, with relatively poor impact strength and low thermal degradation temperature limiting its applicability. ${ }^{\mathbf{3 9 , 4 0}}$ Relatively poor strength, coupled with its hydrophobicity, semicrystalline properties, limited thermal processability, lack of reactive functional groups along the polymer backbone and high cost constitute the majority of its limitation in wide industrial and medical applications..$^{39,45}$ Accordingly, to compete with the low-cost and flexible commodity polymers and upgrade the PLA performance, considerable research effort is being carried out. These attempts include modifying PLA with plasticizers, blending with other polymers, ${ }^{51}$ copolymerization, and incorporation of fillers. ${ }^{37,45,52}$

3.1.1. Plasticizers for poly(lactic acid). Low molecular weight compounds such as oligomeric lactic acid, glycerol, triacetin, and low molecular weight citrates, ${ }^{17}$ partial fatty acid esters $^{53,54}$ are common plasticizers of PLA. A large number of investigations have also been reported on blending PLA with various polymers as plasticizers, for example, thermoplastic starch (TPS), ${ }^{51}$ poly(ethylene oxide), ${ }^{55,56}$ poly(ethylene

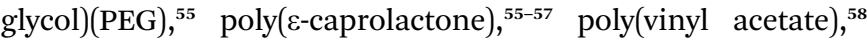
poly(hydroxy butyrate), ${ }^{59}$ cellulose acetate, ${ }^{60}$ poly(butylene succinate), ${ }^{61}$ and poly(hexamethylene succinate), ${ }^{\mathbf{6 1}}$ to improve its flexibility. Most of the resulting plasticized PLA materials exhibited better impact resistance, increased deformation at break and improved resilience. Table 1 reports common monomeric and polymeric plasticizers and their plasticization effects on the glass transition temperature and mechanical property of PLA.

The results in Table 1 show that all citrates at $20 \%$ concentration reduced the glass transition temperature and improved the flexibility while reducing the tensile strength of the PLA control. A significant improvement of elongation at break was achieved at the expense of tensile strength. Ljungberg and Wesslen ${ }^{63}$ also investigated the use of triacetin, tributyl citrate, triethyl citrate, acetyl tributyl citrate, acetyl triethyl citrate as potential plasticizers of PLA and reported a drastic lowering of the glass transition temperature of PLA at concentrations as low as $15 \%$ resulting in a homogeneous and flexible film. However, it was reported that the migration of citrates onto the film surfaces during aging, especially the low molecular weight citrates, was a major challenge. ${ }^{17}$ This issue could be addressed

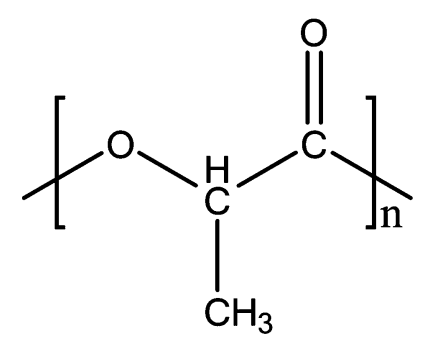

Fig. 2 Basic structure of PLA 


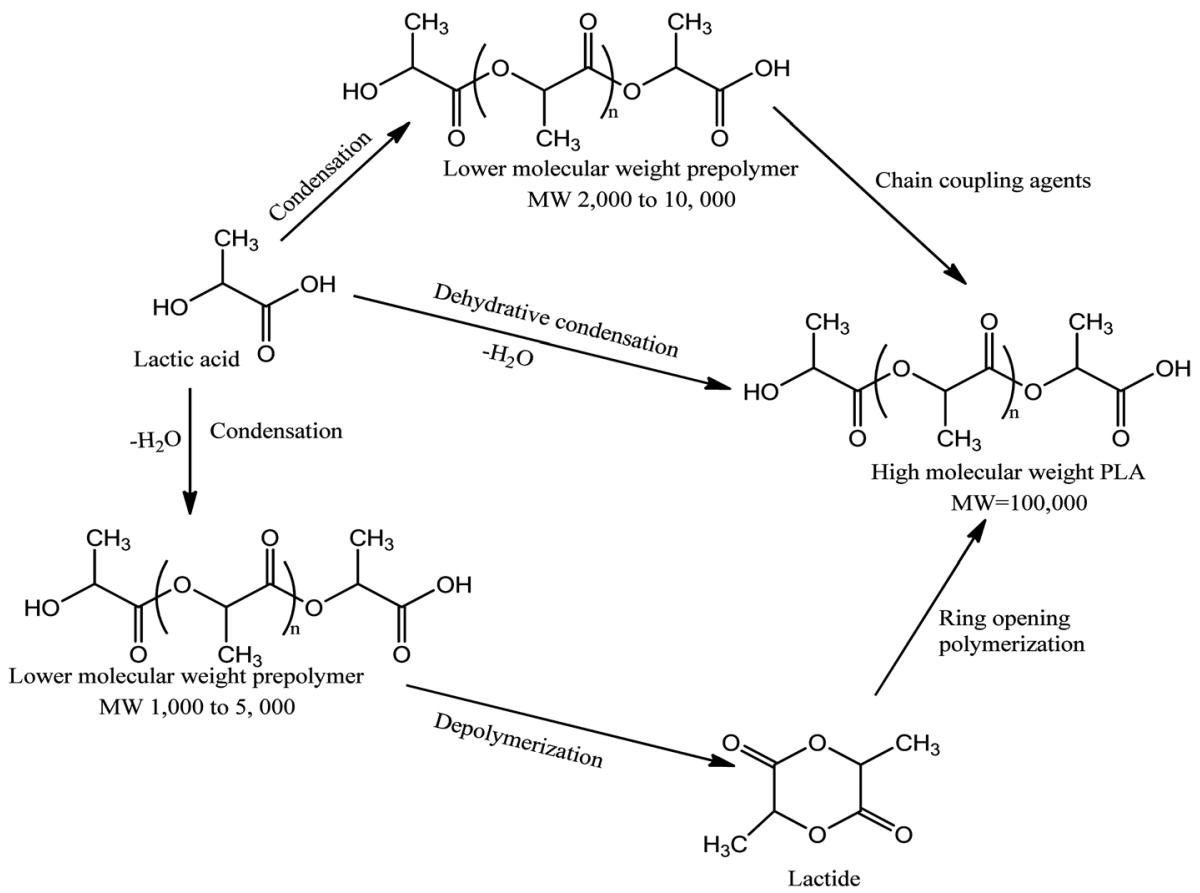

Fig. 3 Synthesis methods for high molecular weight PLA. ${ }^{44,45}$

by increasing the molecular weight. For instance, Ljungberg and Wesslen ${ }^{17}$ transesterified tributyl citrate $\left(M_{\mathrm{W}} 360 \mathrm{~g} \mathrm{~mol}^{-1}\right)$ with diethyl glycol that resulted in two oligomeric plasticizers with higher molecular weights $\left(M_{\mathrm{W}} 4500 \mathrm{~g} \mathrm{~mol}^{-1}\right.$ and $63600 \mathrm{~g}$ $\mathrm{mol}^{-1}$ ). The investigation of the effects of these oligomers on thermo-mechanical and aging properties of PLA shows that both oligomers did not lower the $T_{\mathrm{g}}$ as greatly as monomeric citrates. Among the two oligomeric plasticizers, a relatively larger reduction in $T_{\mathrm{g}}$ was achieved by the oligomer with the lower molecular weight.

Similarly, molecular weight variation, concentration and the presence of polar amide groups of plasticizers can positively interact with PLA chains, affecting the compatibility between PLA and the plasticizer and controlling elongation and morphological stability that result in leaching during aging or use. ${ }^{17,63}$ The plasticizer with lower molecular weight that resulted in lower $T_{\mathrm{g}}$ of PLA may also facilitate the migration of the plasticizer from the bulk of the material compared to the higher molecular weight plasticizer. ${ }^{17}$ The effect of triacetin (0-30\%) and tributyl citrate $(0-25 \%)$ loading on PLA was studied ${ }^{63}$ and an almost linear decrease in $T_{\mathrm{g}}$ with the increase of plasticizer content was observed.
3.1.2. Other methods of improving PLA performance. New PLA toughening strategies using citrate family (tributyl $O$-acetylcitrate and tributyl citrate) to improve the PLA ductility were reported by Hassouna et al. ${ }^{64}$ This strategy involves grafting of tributyl citrate onto neat and maleic anhydride modified PLA with tributyl $O$-acetylcitrate..$^{62}$ The maleation of PLA was carried out by reactive extrusion with the aim of incorporating hydroxyl functional groups into the PLA. The neat PLA and hydroxyl functionalized PLA were then copolymerized with tributyl citrate that already contains a hydroxyl functional group. Such toughening was shown to drastically decrease the $T_{\mathrm{g}}$ of PLA. However, the grafting reaction of tributyl citrate into anhydridegrafted-PLA revealed a shift of PLA $T_{\mathrm{g}}$ toward higher values compared to neat PLA grafted with tributyl citrate. After six months of aging, no phase separation was observed and no major leaching phenomenon was noticed in both cases. These observations indicated that the mobility restriction as a result of hydrogen bonding occurring between PLA and tributyl citrate as well as the grafting reaction of tributyl citrate into anhydridegrafted-PLA diminished the leaching phenomena.

Maglio et al. ${ }^{55}$ studied the copolymerization of PLA with poly(e-caprolactone) (PCL) and poly(oxyethylene) (PEO) to<smiles>C[C@@H]1OC(=O)[C@H](C)OC1=O</smiles>

(a)<smiles>C[C@@H]1OC(=O)[C@H](C)OC1=O</smiles>

(b)<smiles>C[C@@H]1OC(=O)[C@H](C)OC1=O</smiles>

(c)

Fig. 4 Chemical structures of dimeric (a) D-lactide, (b) L-lactide and (c) meso-lactide. 
Table 1 Mechanical and thermal performance of PLA plasticized with different modifiers

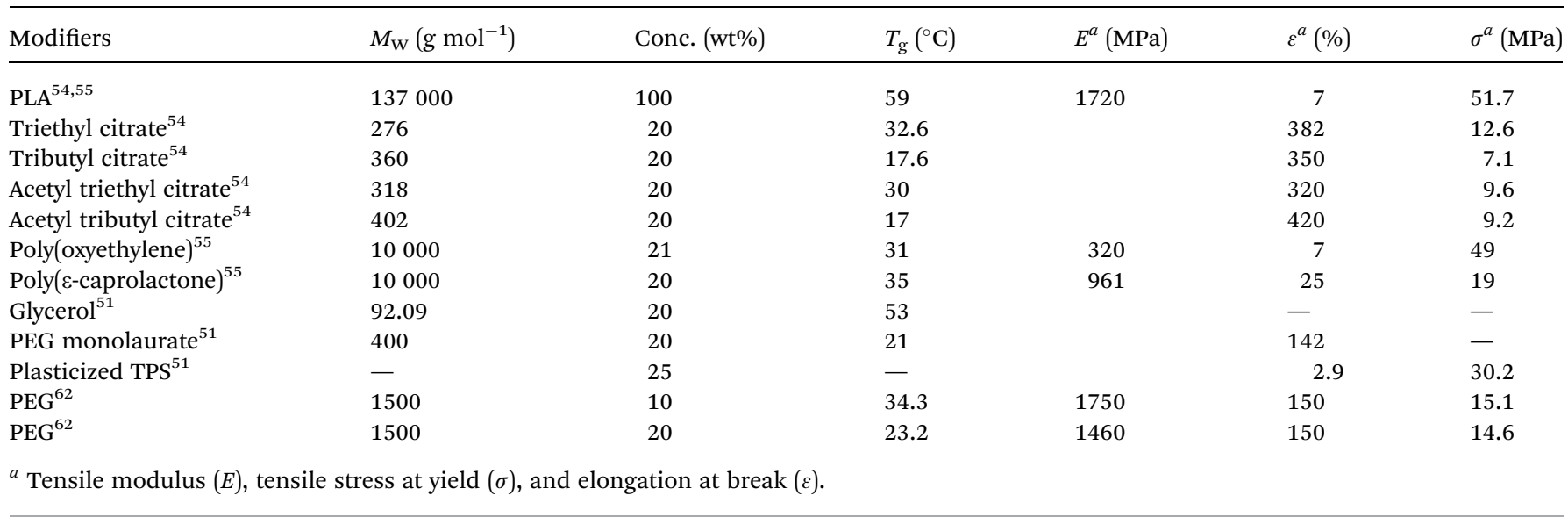

improve the brittleness and reduce $T_{\mathrm{g}}$. The copolymers obtained as a result exhibited high elongations at break and as a result much lower tensile moduli than the PLA pure polymer (Table 1). The $T_{\mathrm{g}}$ of the copolymers was also much lower than that of the original PLA. A recent study by Hassouna et al. ${ }^{62}$ investigated grafting of poly(ethylene glycol) (PEG) onto PLA through reactive extrusion to develop plasticized PLA. It was shown that the $T_{\mathrm{g}}$ and modulus were invariably reduced. In all cases, both $T_{\mathrm{g}}$ and elastic modulus were dependent on the content of PEG grafted onto the PLA. The in situ reactive grafting of PEG onto PLA exhibited a marked $T_{\mathrm{g}}$ reduction than the blending option. Other plasticizers of PLA reported in the literature include epoxidized soybean oil, ${ }^{65}$ ionic liquids, ${ }^{66}$ mixed plasticizers, ${ }^{67}$ etc.

In summary, it can be pointed out that several studies have demonstrated that plasticizers play a significant role in determining the performance properties of PLA plastics. Plasticizers can solve most of the problems that occur during processing or in final use. New characteristics of PLA observed during plasticization may also pave the way to novel applications. The limitations of the currently studied PLA plasticizers include leaching during use, lack of thermal stability, need for offering more ductility and more performance, biocompatibility issues, cost, need for high percentage loading to lower price of PLA, need for a bio-based plasticizer that reduces the overall carbon footprint, etc.

\subsection{Polyhydroxyalkanoates (PHAs)}

Microbial-produced PHAs are fully biodegradable bio-polyesters produced by a wide variety of microorganisms for internal carbon and energy storage as part of their survival mechanism. ${ }^{68,69}$ PHAs, also known as poly(4-alkan-2-oxelanones) according to IUPAC naming, have attracted much attention recently as alternative polymeric materials that can be produced from renewable and biowaste resources. PHAs, with the general structure shown in Fig. 5, vary widely in their structure and properties (flexibility, crystallinity, melting temperature, etc.), depending on the producing microorganisms, the conditions of biosynthesis and the type of carbon source. ${ }^{70}$ PHAs are piezoelectric, perfectly isotactic/optically active and biocompatible thermoplastic polyesters amenable to melt-processing into various final forms. ${ }^{7-74}$ High molecular weight PHAs have attracted considerable attention as potential replacements for non-degradable commodity plastics (e.g. polyethylene and polypropylene), as well as biodegradable and biocompatible biomaterials for implant purposes. ${ }^{72,75}$

Poly(3-hydroxybutyrate) (PHB), R = methyl, being the first among the isolated PHAs, is the most extensively studied PHA produced in nature in the presence of excess carbon by bacteria as storage granules providing food, energy and reducing power. $^{76,77}$ This polymer and its copolymer with polyhydroxyvalerate to make poly(3-hydroxybutyrate-co-3-hydroxyvalerate) (PHBV) are at present the only known PHAs relevant for practical applications. ${ }^{78}$ PHB and PHBV are completely biodegradable in the environment and can be extruded, moulded and spun on conventional plastic processing equipment. $^{71,79}$ These features make these polymers an ideal candidate for the production of biodegradable packaging materials and other disposable articles. ${ }^{79}$ However, the industrial scale production of PHB/PHBV is hindered by roadblocks. Thermal processing is challenging because of their relative low decomposition temperatures near their melting points, pronounced brittleness, very low deformability and susceptibility to a rapid thermal degradation. ${ }^{78,80}$ Furthermore, the current cost of production of PHB is high compared to other high-volume synthetic plastics. $^{70,78}$ Because of its limited thermal stability, the melt flow index changes rapidly with time

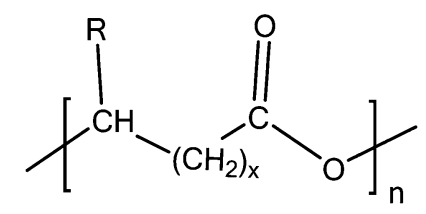

Fig. 5 General structure of PHAs. $n=1$ ( $R=$ hydrogen, poly(3-hydroxypropionate); $\mathrm{R}=$ methyl, poly(3-hydroxybutyrate); $\mathrm{R}=$ ethyl, poly(3-hydroxyvalerate); $\mathrm{R}=$ propyl, poly(3-hydroxyhexanoate); $\mathrm{R}=$ pentyl, poly(3hydroxyoctanoate); $R=$ nonyl, poly(3-hydroxydodecanoate)), $n=2(R=$ hydrogen, poly(4-hydroxybutyrate)), and $n=3(\mathrm{R}=$ hydrogen, poly(5-hydroxyvalerate)). 
and its volatile decomposition products need to be handled safely. PHB's slow crystallization rates also lead to tacky products (e.g. fibres, films, etc.). ${ }^{70}$ Its copolymer with valerate (PHBV) has overall better properties, especially regarding improved toughness with an acceptable loss of strength and modulus. ${ }^{73}$ However, the present large-scale production cost of $\mathrm{PHBV}$ remains higher than that of $\mathrm{PHB} .^{78}$

The toughness and processability of PHB can be improved by incorporation of the hydroxyvalerate (HV) monomers in the bacterial fermentation process. ${ }^{81}$ While PHBV with a high HV content has high flexibility, low crystallinity, and low crystallization rate, it compromises the yield strength and Young's modulus of $\mathrm{PHB}$, which can result in rubbery materials, meanwhile, it increases the cost of materials. ${ }^{\mathbf{1 1}}$ Various approaches, such as use of nucleating agents, plasticizers and agents that promote crystallization of the polymer, modification of the polymer structure, blending, etc., have been carried out to overcome the processing and product difficulties and other shortcomings. ${ }^{70,73,78,82}$

3.2.1. Plasticizers for PHAs. The use of monomeric and polymeric plasticizers of PHA lowers the glass transition temperature and the melting points, allowing processing at lower temperature and avoiding thermal degradation. ${ }^{79,82}$ In addition, plasticizers improve both toughness and softness of the polymer by decreasing its crystallinity, weakening the intramacromolecular bonding and facilitating conformational changes. ${ }^{83}$ The plasticization of PHBV using soybean oil, epoxidized soybean oil, epoxidized linseed oil, dibutyl phthalate, polyester plasticizer (Lapol 108), triethyl citrate, acetyl tributyl citrate and polyethylene glycol has been described in the literature $^{82-88}$ as shown in Table 2.

It is observed from Table 2 that the plasticizers induced depression of glass transition temperature and improvement in the elongation at break with all the plasticizing additives used, with the exception of triglyceride soy oil. From Park and Choi's study, ${ }^{\mathbf{8}}$ triethyl citrate was the most effective plasticizer in terms of reduction of the glass transition temperature as well as in terms of improvement of the impact strength and elongation. The difference in the effectiveness of these plasticizers can be attributed to the variation in the combined effect of chemical structure, molecular weight compatibility or solubility of the plasticizer with the polymer. ${ }^{83}$ On the other hand, studies of impact strength and elongation properties by Seydibeyoglu et $a l .{ }^{88}$ showed that functionalized oils such as epoxy soyate are much more effective than triglycerides of epoxidized soybean or linseed oil. This might be due to the better reactivity of epoxy soyate than the counterpart triglycerides owing to its lower molecular size and simple molecular structure.

The use of low molecular weight, biodegradable and nontoxic compounds as plasticizing additives such as dibutyl sebacate (DBS), dioctyl sebacate (DOS), polyethylene glycol (PEG), Lapro1503 (L503), Lapro15003 (L5003), and a nonpolar polymer polyisobutylene (PIB) with concentration up to $50 \mathrm{wt} \%$ was investigated to improve the deformative characteristics of PHB. ${ }^{89}$ These plasticizers were completely compatible with the polymer and formed a monophase system in mixtures of up to 15-20 wt\%. Conversely, when the concentration was beyond 20 $\mathrm{wt} \%$ the system becomes considerably weak, because of overloading. The majority of the plasticizers examined by the author cause a considerable decrease in crystallization temperature and improvement of mechanical properties. Other plasticizers reported in the literature include dodecanol, lauric acid, tributyrin, and trilaurin..$^{90}$

3.2.2. Other methods of toughening. Blending of $\mathrm{PHB}$ or PHBV-based materials with polymers such as poly(butylene succinate), ${ }^{81}$ poly(ethylene succinate), ${ }^{81,91}$ polyethylene, ${ }^{92}$ polypropylene, ${ }^{92}$ poly( $\varepsilon$-caprolactone),${ }^{93}$ poly(lactic acid),${ }^{93,94}$ etc. has been extensively examined, and improvements of mechanical and thermal properties were reported. However, in most of these studies poor interfacial adhesion and phase separation of the PHB (V) and the other polymer blends was reported. These limitations could be improved through the use of a compatibilizing agent, functionalization, chain extension, controlled chemical crosslinking and optimizing the process conditions.

Ma et al. ${ }^{81}$ used a free radical initiator (dicumyl peroxide) to induce compatibilization and partial crosslinking between PHB and PBS. The resulting compatibilized blends were shown to have a smaller particle size, improved interfacial adhesion and consequently resulted in improved tensile strength, impact toughness and elongation at break. Sadi et al. ${ }^{95}$ evaluated the compatibilization efficiency of polypropylene/PHB blends with copolymers such as poly(propylene- $g$-maleic anhydride), poly(ethylene-co-methyl acrylate), poly(ethylene-co-glycidyl methacrylate), and poly(ethylene-co-methyl-acrylate-co-glycidyl methacrylate). Their study showed that poly(propylene- $g$-maleic anhydride), having the strongest adhesion between the phases, was the most efficient in terms of improving the mechanical performance of the blend.

Table 2 Effect of plasticizing modifiers on the glass transition temperature and mechanical properties of PHBV

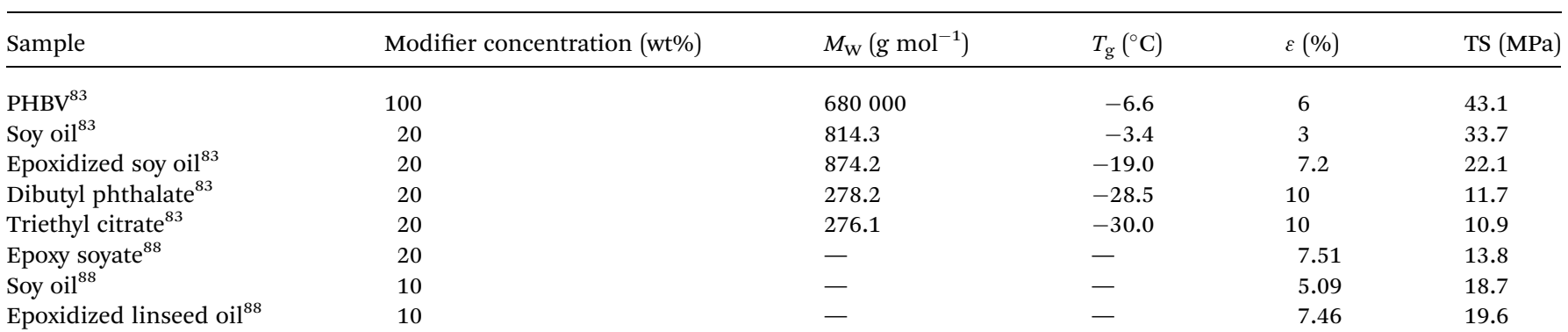


Optimization of the processing conditions, taking the relationship among structure, composition, and polymer properties into account, is of particular importance as well. ${ }^{\mathbf{9 6}}$ High shearing rates during process operations such as extrusion (10$100000 \mathrm{~S}^{-1}$ ) and injection molding (1000-100000 $\left.\mathrm{S}^{-1}\right)^{97}$ in addition to the heating applied during processing are expected to change the molecular weight and as a result its performance. For instance, Yamaguchi et al. ${ }^{98}$ reported $25-30 \%$ molecular weight reduction of $\mathrm{PHB}$ through shearing of $\mathrm{PHB}$ at $180^{\circ} \mathrm{C}$, at a shear rate of $6.3 \mathrm{~s}^{-1}$ within 5 min interval in addition to an order-of-magnitude decrease in shear viscosity.

\subsection{Thermoplastic starch (TPS)}

Starch, a polysaccharide of granular structure, is one of the most attractive feedstock for the development of biodegradable polymers because it is relatively inexpensive, abundant and renewable. Starch plays an important role both in the development of the commercialized bio-based plastics ${ }^{99}$ and in the bioethanol industry. The role of starch in the development of biobased plastics could be in the development of (a) thermoplastic starch (TPS) plastics where TPS is obtained through direct modification of starch, (b) poly(lactic acid) where its feedstock (lactic acid) is originated from starch derived sugars fermentation and (c) PHAs where starch derived sugars are used as a carbon source for the microorganisms producing PHAs.

Starch is composed of two homopolymers of D-glucose: the linear (1,4)-linked $\alpha$-D-glucan amylase, typically constituting about $30 \%$ of starch depending on the source of starch, and a highly branched (1,6)-linked $\alpha$-D-glucan amylopectin (Fig. 6). Commonly, amylopectin takes part in the formation of a crystalline structure and amylose does not. ${ }^{\mathbf{1 0 0}}$ Virgin starch is brittle and difficult to process into articles due to its relatively high glass transition and melting temperatures. The $T_{\mathrm{g}}$ of virgin dried starch is estimated to be approximately $240{ }^{\circ} \mathrm{C},{ }^{101}$ which is above the starting point of its thermal degradation (about 220 $\left.{ }^{\circ} \mathrm{C}\right) .{ }^{102}$ High $T_{\mathrm{g}}$ and brittleness of starch are mainly caused by the presence of strong inter- and intra-molecular hydrogen bonds between the starch macromolecules. ${ }^{101}$ Furthermore, TPS polymers based solely on starch are extremely water sensitive ${ }^{\mathbf{1 0 3}}$ and can suffer from significant molecular weight change during processing (extrusion or injection molding). ${ }^{\mathbf{1 0 4}}$ These drawbacks limit the possible shapes that can be imparted to the materials into films with adequate mechanical properties ${ }^{\mathbf{1 0 5}}$ and thus of limited practical value. Therefore, starch must be modified to breakdown the crystalline granules, decrease the $T_{\mathrm{g}}$ and melting temperature $\left(T_{\mathrm{m}}\right)$ either by incorporating plasticizers, ${ }^{\mathbf{1 0 6}}$ blending with other polymers, ${ }^{51,52}$ chemical modification or combinations before they can be processed into plastics. ${ }^{\mathbf{1 0 7}}$

3.3.1. Plasticizers for thermoplastic starch. During the thermoplastic processing of starch, typically between 70 and 90 ${ }^{\circ} \mathrm{C}$ in the presence of a plasticizer (e.g. water), a semicrystalline granule of starch is transformed into a homogeneous material with hydrogen bond cleavage between starch molecules. This process, called gelatinization, leads to loss of crystallinity ${ }^{\mathbf{1 0 6}}$ and is associated with the loss of double helices as well as with the loss of lamellar and long range crystalline structure. ${ }^{108}$ Plasticizers penetrate starch granules and destroy the inner hydrogen bonds of starch, and eliminate starch-starch interactions because they are replaced by starch-plasticizer interactions. The plasticized moldable thermoplastic material, called TPS, is fit for injection molding, extrusion or blow molding similar to other synthetic thermoplastic polymers. ${ }^{109}$

There are several substances used as plasticizers for the preparation of thermoplastic starch. Some of the most studied and reported TPS plasticizers in the literature include polyols such as glycerol, glycol, sorbitol, xylitol, maltitol, ethylene glycol, propylene glycol, butanediol; ${ }^{\mathbf{1 0 7 , 1 1 0 , 1 1 1}}$ sucrose, fructose, mannose,${ }^{112}$ fatty acids (such as myristate or palmitate), ${ }^{113}$ etc. It is also necessary to note that water is a good plasticizer of starch. However, the use of water alone as a plasticizer is not preferable because the resulting product will be brittle when
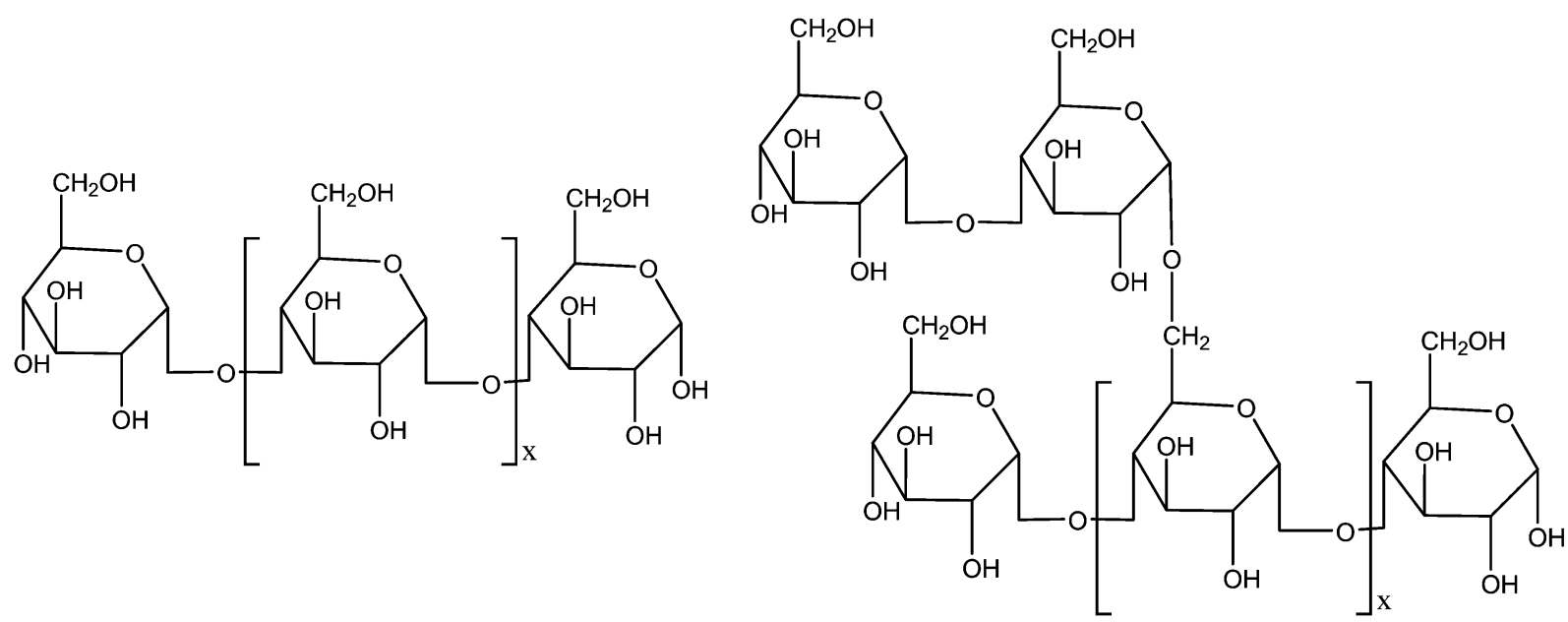

(a)

Fig. 6 Structure of starch polymers (a) amylose and (b) amylopectin. (b) 
equilibrated with ambient humidity ${ }^{\mathbf{1 1 0}}$ and due to volatilization of water. Glycerol, a classical plasticizer of starch, is perhaps the most widely studied and used polyol plasticizer of TPS. This is because of its low cost, nontoxicity (for food and biomedical application) and high boiling point $\left(292{ }^{\circ} \mathrm{C}\right)$. Moreover, the hydrolysis and/or transesterification of lipids (triglycerides) into fatty acids for the biodiesel industry produce glycerol as a byproduct. Utilizing such by-products provides glycerol with an additional market driver in addition to the opportunity of improving the economics of both the biodiesel and the bioplastic industries. Nonetheless, glycerol is known to leach out during aging and humidity exposure, a major limitation for large scale applications.

The properties of plasticized starch can be tuned by changing the temperature of processing, water content and the properties and amount of plasticizers. For instance, Yu et al. ${ }^{101}$ reported that the elongation at break of the thermoplastic starch is significantly improved by plasticization with glycol, glycerol and hexylene glycol. In addition, the thermal properties of plasticized starch are a function of water and plasticizer content. ${ }^{110,114}$ The source of starch is also important for the property of TPS. This is because starches from various sources have different amylose/amylopectin ratios, molecular weights, molecular weight distributions and granular size crystallinity (Fig. 7). This as a result influences the gelatinization and glass transition temperatures ${ }^{\mathbf{1 1 5 , 1 1 6}}$ that are directly correlated with the thermoplasticity of the TPS. The effect of various plasticizers at different concentrations on the gelatinization temperatures, thermal stability, and glass transition temperature has been studied and reported in the literature. Some of the plasticizers and their effects are reviewed and shown in Table 3.

Abdorreza et al. ${ }^{117}$ showed that the type and concentration of plasticizers govern the heat sealability as well as the seal strength of sago starch based films. The same authors showed that sorbitol-plasticized films exhibited significantly better heat sealability than did the glycerol type. However, the highest seal strength was obtained with a combination of sorbitol and glycerol. The effect of starch gelatinization in the presence of high molecular weight polyol plasticizers and water was also studied under static and dynamic conditions by Taghizadeh and Favis. ${ }^{108}$ Their investigation showed that glycerol and sorbitol exhibited similar gelatinization temperatures, while an ascending $T_{\mathrm{g}}$ was observed from glycerol to diglycerol and polyglycerol attributed to the viscosity and molecular weight increase and hydroxyl bond density diminution of the latter two plasticizers.

Other plasticizers such as urea, formamide, combinations of urea and formaldehyde, ${ }^{125}$ used with thermoplastic corn starch at different concentrations were also reported. Property evaluation by Ma et al. ${ }^{125}$ showed that mixtures of urea $(20 \mathrm{wt} \%)$ and formamide (10 $\mathrm{wt} \%$ ) plasticized TPS exhibited better thermal stability, water resistance and better mechanical properties than conventional glycerol plasticized TPS. According to Ma et al. ${ }^{\mathbf{1 2 5}}$ the reasons behind such property improvement with the urea-formamide mix plasticizer could be due to the formation of more stable and stronger hydrogen bonds with the hydroxyl groups of starch molecules than with glycerol. Yang et $a{ }^{\mathbf{1 2 6 , 1 2 7}}$ reported ethylenebisformamide, synthesized from methyl formate and ethylenediamine, as a novel and effective plasticizer of corn starch and potato starch. Ethylenebisformamide was shown to be effective in destroying the crystalline morphology of the native starch granule and conversion into a homogeneous phase TPS through plasticization and extrusion under shear and pressure. The morphology of the native crystalline starch and the homogeneous plasticized starch at $25 \%$ and $30 \%$ ethylenebisformamide loading was studied by scanning electron microscopy (SEM) ${ }^{\mathbf{1 2 6 , 1 2 7}}$ and shown in Fig. 7.

The SEM study (Fig. 7) clearly showed that the action of ethylenebisformamide and temperature processing (in this case extrusion) resulted in destruction of the crystalline native starch granules (Fig. 7a and d) morphology to form a continuous phase of TPS having a different crystallinity as further confirmed by Xray diffraction crystallography. ${ }^{\mathbf{1 2 6 , 1 2 7}}$ The effect of plasticizer
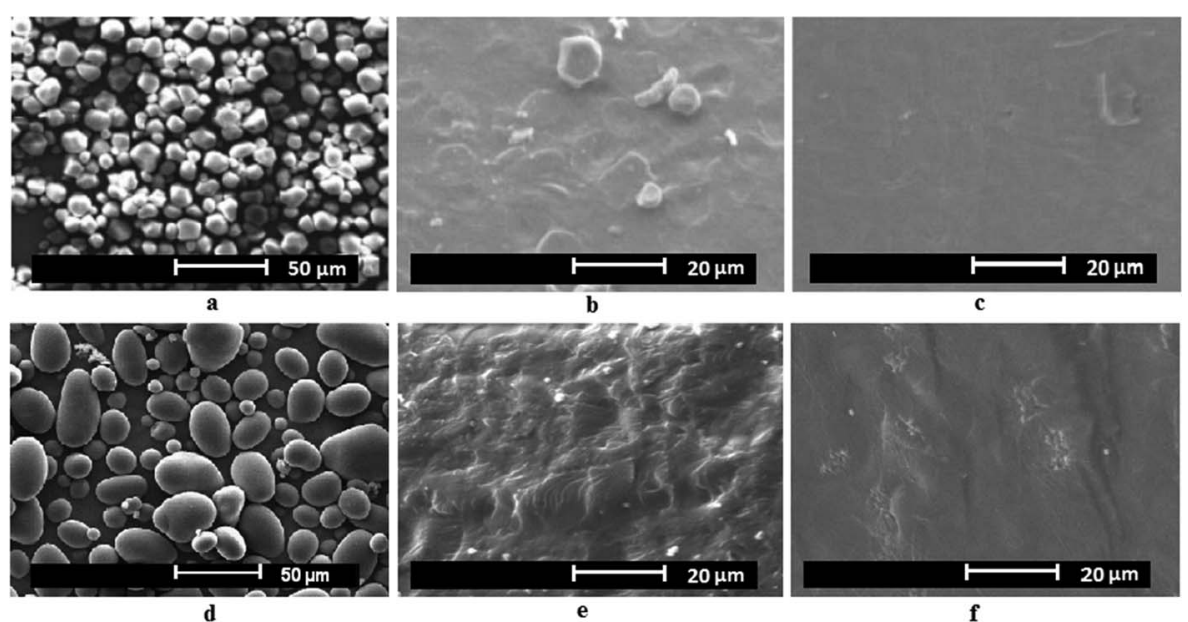

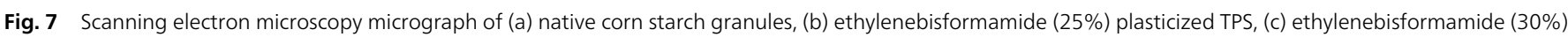
plasticized TPS (adapted from: ref. 126 John Wiley \& Sons, copyright (c) 2006) and (d) native potato starch. 
Table 3 Common plasticizers for some of the common starch sources

\begin{tabular}{|c|c|c|c|c|}
\hline Starch source & Plasticizer & $\begin{array}{l}\text { Plasticizer concentration } \\
(\mathrm{wt} \%)\end{array}$ & $\begin{array}{l}\text { Gelatinization } \\
\text { onset }\left({ }^{\circ} \mathrm{C}\right)\end{array}$ & $\begin{array}{l}\text { Gelatinization peak/ } \\
\text { conclusion }\left({ }^{\circ} \mathrm{C}\right) / T_{\mathrm{g}} \\
\end{array}$ \\
\hline \multirow{2}{*}{$\begin{array}{l}\text { Wheat starch in the } \\
\text { presence of water }{ }^{108}\end{array}$} & Glycerol & 65 & 74.7 & $91.5^{a}$ \\
\hline & Diglycerol & 65 & 90 & $115^{a}$ \\
\hline \multirow[t]{2}{*}{ Sago starch ${ }^{117}$} & Starch (control) & 0 & 123.7 & $157.2^{b}$ \\
\hline & Glycerol & $30,40,50$ & $149,152,141$ & $169,175,164^{b}$ \\
\hline Corn $\operatorname{starch}^{118,119}$ & 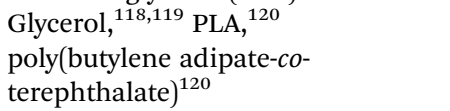 & - & - & - \\
\hline \multirow[t]{3}{*}{ Potato starch ${ }^{111,121}$} & Glycerol-xylitol & 40 & - & $-66.4^{c}$ \\
\hline & Glycerol-sorbitol & 40 & - & $-69.3^{c}$ \\
\hline & Xylitol-sorbitol & 40 & - & $-44.1^{c}$ \\
\hline & & & & \\
\hline
\end{tabular}

loading had also an effect on the continuity of the plasticized TPS phase. Higher concentrations resulted in more uniform phases for the studied loading range. Possible hydrogen bond formation between ethylenebisformamide and $\operatorname{starch}^{\mathbf{1 2 6}}$ during plasticization is shown in Fig. 8 below. The hydrogen bonds formed can be stronger than the intra and intermolecular bonds in starch, and as a result corn and potato starch were effectively plasticized with ethylenebisformamide. ${ }^{126,127}$ In general, besides the plasticizer type, the quantity of plasticizer used and the processing method applied also affect the physical, thermal and mechanical properties of the resulting starch based bioplastics. For example, Flores et al. ${ }^{\mathbf{1 2 8}}$ studied and reported the effect of different gelatinization and drying techniques on the performance of glycerol plasticized starch films. The authors ${ }^{128}$ finding shows that gelatinization and drying techniques used to obtain TPS films affected network characteristics that as a result determines the changes in physical properties potentially affecting the film performance as well.

In recent studies, the use of novel multifunctional ionic liquid plasticizers such as 1-allyl-3-methylimidazolium chloride $^{\mathbf{1 0 9 , 1 2 9}}$ and 1-butyl-3-methyl imidazolium chloride as a plasticizer $^{130}$ and a compatibilizing agent ${ }^{131}$ of starch has been reported. Ionic liquids, organic salts that are liquid at ambient temperature, are gaining interest because of their unique properties including non-volatility, non-flammability, low viscosity, chemical and electrochemical stability. ${ }^{\mathbf{1 3 2}}$ These liquids (examples of structures are shown in Fig. 9) have strong hydrogen bond forming abilities with starch owing to their high concentration of chloride ions. TPS plasticized using 1-butyl-3methylimidazolium chloride shows less hygroscopicity and a much higher elongation at break in the rubbery state than the control glycerol-plasticized TPS samples. ${ }^{130}$ The potential application of ionic liquids plasticized starch as solid biopolymer electrolytes was also reported by Wang et al. ${ }^{129}$ This paves the way for a wide variety of potential applications of TPS bioplastics such as antistatic plastics, electronic shielding, biosensor, and environmentally sensitive membranes.

3.3.2. Other methods of improving performance of TPS. Chemical modification can also be an effective method of improving the processability and product performance of TPS. For example, hydroxylation, ${ }^{\mathbf{1 3 3 , 1 3 4}}$ acylation, ${ }^{135}$ oxidation ${ }^{\mathbf{1 3 6}}$ and acetylation $^{\mathbf{1 3 6 , 1 3 7}}$ of starch by substituting the ester or ether groups for the hydroxyl were reported to improve the processing behavior, hydrophobicity and mechanical properties. The synthesis of thermoplastic starch acetate with a high degree of substitution through acetylation of starch is one of the common

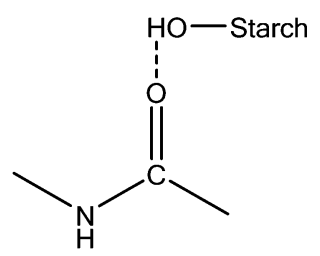

a

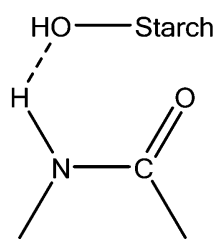

b<smiles>CC(=O)N(C)[C@@H](C)O</smiles>

c

Fig. 8 Possible hydrogen bonds between ethylenebisformamide and starch. ${ }^{126}$ 


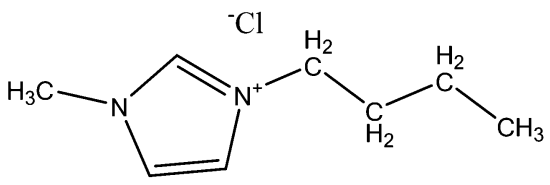

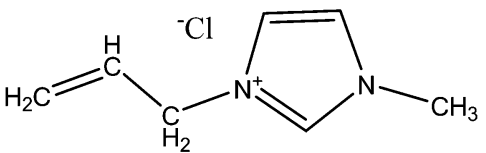

b

Fig. 9 Chemical structure of ionic liquids 1-allyl-3-methylimidazolium chloride and 1-butyl-3-methyl imidazolium chloride.

chemical modifications of starch. ${ }^{137,138}$ The starch acetates were shown to have higher thermal stability and hydrophobicity due to the reduction of the hydroxyl group with the acetylation. Some of the chemical modifications may reduce biodegradability, biocompatibility and generate some toxic chemical byproduct during synthesis. ${ }^{139}$ On the other hand, some of the chemically modified starch (e.g. starch acetate) could be biocompatible and safe enough to be used in tissue engineering and other medical applications. ${ }^{138}$

Other toughening modifications recently reported in the literature to improve performance and overall economics of TPS based polymers include blending of TPS with protein, ${ }^{\mathbf{1 3 1}} \mathrm{PVA},{ }^{\mathbf{1 4 0}}$ polycaprolactone, polyhydroxybutyrate, polymethacrylate, polystyrene mostly in the presence of urea and polyol plasticizers. ${ }^{103,120}$ Surface modifications such as polymeric surface coating, ${ }^{109}$ chemical and photo crosslinking of TPS and blends were also shown to reduce surface hydrophilic characteristics and improve water resistance, increase the tensile strength and Young's modulus while decreasing the elongation at break. ${ }^{140-142}$ In summary, starch based plastics have grown to represent a major portion of the biodegradable polymer market. The commercial success of TPS polymers is hugely affected by the source, safety, quality, cost and functionality of plasticizers. Selective plasticization/toughening methods of TPS provide an attractive base for developing starch polymers that can be used as biodegradable and renewable packaging materials, environmentally sensitive membranes, and in biomedical and pharmaceutical applications such as drug and protein carriers, tissue engineering applications, etc.

\subsection{Protein based plastics}

Proteins are renewable, biodegradable and optically active natural ${ }^{143}$ polymers produced by animals, plants and bacteria. Until recently proteins have been utilized exclusively in the food industries. Recent studies on non-food uses of agricultural feedstock initiated an interest in protein based plastics as well. Due to the continuous and cohesive matrix forming ability of proteins, various proteins of both plant and animal origin have received attention for the production of biodegradable plastics, edible films and sheets. ${ }^{\mathbf{1 4 4 , 1 4 5}}$ Furthermore, microencapsulating agents and active compounds in pharmaceutical applications, ${ }^{\mathbf{1 4 6 , 1 4 7}}$ adhesives, blend and composite materials, ${ }^{\mathbf{1 4 2 , 1 4 8}}$ wound dressing ${ }^{149}$ and bionanocomposites ${ }^{142,150}$ can be produced. Protein based biomaterials can also promote tissue regeneration, such as new bone growth, ${ }^{\mathbf{1 4 9}}$ integrate into blood clots and stimulate collagen deposition, and stimulate cells to produce new tissue, with no need for expensive growth factors. ${ }^{151}$ Plant proteins that can be used for bio-based plastics include soy protein, ${ }^{150}$ corn zein, ${ }^{33}$ wheat protein, ${ }^{152,153}$ cottonseed protein, ${ }^{154}$ sunflower protein, ${ }^{155}$ etc. Animal proteins such as blood meal, ${ }^{\mathbf{1 5 6}}$ gelatine and collagen, ${ }^{\mathbf{1 5 7}}$ keratin and feather quill, ${ }^{158}$ egg protein, ${ }^{159}$ whey protein, ${ }^{155}$ meat and bone meal $^{160,161}$ can also be used as a feedstock of such bio-based plastics (Table 4).

Proteins are interesting biomaterials based on 20 amino acids which confers a wide range of functional and film-forming properties as a function of various extrinsic or intrinsic conditions such as plasticizer type and concentration. ${ }^{\mathbf{1 6 2}}$ The major drawback of protein-based plastics, with the notable exception of keratin, is their sensitivity towards relative humidity. ${ }^{\mathbf{1 6 3}}$ For example, Zheng et $a .^{163}$ reported that soy protein sheets submerged in water for $20 \mathrm{~h}$ absorbed up to $180 \%$ water. In addition, protein films and coatings are often quite stiff and brittle due to extensive intermolecular interactions between protein chains through hydrogen bonding, electrostatic forces, hydrophobic bonding and disulfide cross-linking. ${ }^{34}$ Thus, thermoplastic processing of proteins into bio-based plastics is usually accompanied by plasticization and/or other form of modification for the successful development of useful proteinaceous biopolymers. Plasticizers can reduce the aforementioned chain-to-chain interaction and induce flexibility, moisture resistance and ease of processability.

Thermosetting protein plastics processing, on the other hand, occurs through chemical crosslinking that involves the formation of covalent bond bridges between protein chains by using a crosslinking agent. The crosslinkers chiefly target the reaction between themselves and protein functional groups such as primary amines, carboxyl, hydroxyl, and sulfhydryls - of amino acid residues to provide mechanical strength and moisture resistance. ${ }^{\mathbf{1 6 0 , 1 6 1}}$ Protein-polymer grafting is another method of producing a protein based biomaterial usually with complementary advantages of each component. Thermoplastic processing, which involves melting a polymer followed by shaping and cooling, is the most widely adopted method for the production of protein-based bioplastics.

3.4.1. Plasticizers of protein based plastics. Plasticizers of proteins are generally added to the protein matrix during thermoplastic processing such as extrusion or injection molding to improve processability, reduce brittleness and modify the properties of the final structure. ${ }^{\mathbf{1 6 4}}$ Plasticizers added to the protein resin or compound usually consist of low molecular weight, low volatility substances, which mainly compete for hydrogen bonding and electrostatic interactions 
Table 4 Examples of plasticizers, animal and plant derived protein biomass, and the mechanical properties of the biopolymers made

\begin{tabular}{|c|c|c|c|c|c|}
\hline Plasticizer & Protein studied & TS (MPa) & $E(\mathrm{MPa})$ & $\varepsilon(\%)$ & Ref. \\
\hline \multirow[t]{2}{*}{ Urea $(20 \%)$} & Blood meal & 12.3 & 608 & - & 156 \\
\hline & Wheat gluten & - & - & - & 165 \\
\hline & Chicken fibers & 19.0 & 907.9 & 3.3 & 166 \\
\hline Dibutyl tartrate (30\%) & Corn zein & 20 & 1325 & - & 167 \\
\hline \multirow[t]{5}{*}{ Glycerol $(30 \%)$} & Corn zein & 19.3 & 620 & - & 167 \\
\hline & Feather quill & 15.2 & 380.5 & 13.6 & 158 \\
\hline & Chicken feathers & 15.7 & 332.3 & 8.5 & 166 \\
\hline & Peanut proteins & 8.0 & 147.0 & 63.0 & 168 \\
\hline & Sunflower protein & 8.5 & - & 140 & 170 \\
\hline \multirow[t]{2}{*}{ Ethylene glycol (30\%) } & Chicken feathers & 17.8 & 354.0 & 43.8 & 166 \\
\hline & Sunflower protein & 8.7 & - & 23 & 170 \\
\hline & Soy protein & 4.5 & 108.4 & 8.5 & 169 \\
\hline Oleic acid (20\%) & Gelatin & 54 & 2500 & 2.9 & 171 \\
\hline Sorbitol $(20 \%)$ & Gelatin & 52 & 1997 & 4.4 & 171 \\
\hline Mannitol (20\%) & Gelatin & 57 & 2250 & 4.5 & 171 \\
\hline
\end{tabular}

with the protein chains to produce swelling. ${ }^{34}$ Table 4 below summarizes common plasticizers for different protein biomass sources that have been used in the thermoplastic processing of proteins in the literature.

Similar to most other bio-based plastics, the composition, size, and shape of plasticizers influence the mechanical, physical, thermal, moisture permeability and aging behavior of proteinaceous plastics. ${ }^{\mathbf{1 5 8 , 1 6 6 , 1 7 0 , 1 7 1}}$ Orliac et al. ${ }^{\mathbf{1 7 0}}$ demonstrated that sunflower protein isolate films plasticized with different polyalcohols, such as glycerol, ethylene glycol, propylene glycol, polyethylene glycols, and polypropylene glycols, exhibited high mechanical properties, and good moisture impermeability to the level that it can be used for agricultural mulching. Cao et $a l .{ }^{171}$ compared the plasticizing effect of polyethylene glycol (PEG) with different molecular weights $(300,400,600,800$, 1500, 4000, 10 000, 20 000) on gelatin films. The result showed that PEG with lower molecular weight gave better plasticizing effect (higher elongation), lower water vapor permeability and better visual effect. An increase in molecular weight of PEG in contrast induced an increase in the tensile strength, elastic modulus and a decrease in the elongation of gelatin films. Polar groups $(-\mathrm{OH})$ along plasticizer chains are believed to develop polymer-plasticizer hydrogen bonds replacing the polymerpolymer interactions in biopolymer films. ${ }^{172}$ Thus, hydrogen bonding ability of PEGs was affected by factors such as the number of hydroxyl groups per mole, molecular size, solubility and polarity that will explain the observed variation. Recent studies by Ullah et al. ${ }^{\mathbf{1 5 8 , 1 6 6}}$ also demonstrated that the variation in hydrogen bonding interactions between plasticizers (glycerol, diethyl tartrate, propylene glycol and diethyl tartrate) and keratin from poultry feather quills and poultry feather fiber could be responsible for the variation in plasticization efficacy.
The best mechanical properties, transparency, flowability, and processability were observed in the case of ethylene glycol plasticized keratin quill and keratin feather, conceivably because of the formation of strong hydrogen bonding between the ethylene glycol and quill keratin.

Proteins are hydrophilic materials and as such they need to be coupled with adequate plasticizers to reduce the water absorbance of the corresponding plastics. Therefore, extensive attempts to improve moisture barrier properties are being conducted. ${ }^{173-175}$ The introduction of hydrophobic materials such as lipids, long chain fatty acids and waxes incorporated into protein films has shown promising results. ${ }^{173,176,177}$ For instance, Sohail et al. ${ }^{173}$ studied and reported the moisture barrier property improvement of protein biopolymers (casein films), as a result of wax incorporation in the film formation and surface wax coating. The wax application on moisture barrier properties was more efficient in wax-coated casein films than wax incorporated biopolymers. While both wax-coating and incorporation improved the flexibility of the films at the expense of tensile strength reduction, the wax incorporated polymers exhibited better flexibility than the coated ones. Pommet et al. ${ }^{\mathbf{1 7 6}}$ likewise reported an improvement in the water vapor permeability of gluten protein films with the use of saturated fatty acids with an even number of carbons from 6 to 18 (C6:0: hexanoic acid, C8:0: octanoic acid, C10 : 0 : decanoic acid, C12 : 0 : lauric acid, C14 : $0:$ myristic acid, C16 : $0:$ palmitic acid, C18 : $0:$ stearic acid).

Shellhammer and Krochta ${ }^{178}$ studied the effect of lipid type and amount on the plasticization of whey protein biopolymer using beeswax, candelilla wax, carnauba wax and a high melting fraction of anhydrous milk fat. According to the authors, an increase in lipid level decreased the strength of the biopolymers. 
Among the studied lipids, candelilla wax incorporation provided the weakest films, followed by beeswax, milk fat, and carnauba wax. Furthermore, a positive correlation between water vapor permeability of the lipids and the lipid plasticized protein plastics explains the increment in water vapor permeability of some of the biopolymers. Fabra et al. ${ }^{177}$ reported the formation of bilayer structures by saturated fatty acids in sodium caseinate film forming solution that led to water vapor permeability improvement. The self-association of saturated fatty acid molecules occurs to form bilayers of different sizes in the film forming dispersions, and these laminar structures grow and persist in the dried film. The crystal formations as a result greatly limit water vapor permeability and yield rigid nonflexible films that show opacity and low gloss. According to the same authors, ${ }^{177}$ unsaturated fatty acids such as oleic acid did not form laminar structures due to the double bond while it provokes a synergic plasticizing effect with water that seriously increased the water vapor permeability and film flexibility at intermediate relative humidity levels. ${ }^{179}$

The synergetic effects of using mixed glycerol (polar) and oleic acid (amphiphilic) plasticizers on sodium caseinate ${ }^{179}$ and zein protein biopolymers ${ }^{180}$ were also reported recently. According to Ibragimo et al., ${ }^{181}$ the plasticization obtained by glycerol is structural (inter-packet) and that of oleic acid is molecular (intra-packet). These two different molecules with different plasticization mechanisms provide the possibility for their interaction during film formation. The combination of these two plasticizers in zein films exhibited synergy and as a result a change in tensile strength (highest at $3: 1$ ratio of oleic acid to glycerol), decrease in glass transition temperature and change in microscopic molecular structure were observed. ${ }^{180}$

Tummala et al. ${ }^{182}$ reported the use of glycerol, sorbitol and their blend to plasticize and compatibilize soy-protein and polyester amide, and compared their influence on the performance of the resulting biopolymers. While sorbitol plasticized soy-polyester amide plastics were more rigid, with a higher tensile modulus and tensile strength and thermal stability, glycerol plasticized soy-polyester amide plastics had the highest impact strength. The blend of the two on the other hand provided an intermediate tensile strength and modulus. Other types of protein biopolymer modifications reported in the literature include blending of gelling agents such as agar, agargel, phytagel, ${ }^{183}$ incorporation of nanoclays, ${ }^{184}$ etc. A recent study by Kim and Netravali ${ }^{183}$ demonstrated that the blending of gelling agents with soy protein significantly improved the mechanical, thermal stability resistance of the protein biopolymers. This is because of the possible formation of interpenetrating network (IPN) structures between the gelling agents and the protein with a high degree of intermolecular interactions. ${ }^{183}$

3.4.2. Other methods of improving performance of protein based plastics. The most commonly utilized techniques for polymer modifications besides plasticization are blending, grafting, crosslinking, and composite formation, which are all multicomponent systems. ${ }^{185,186}$ While blending is the physical mixing of multiple polymers to obtain the requisite properties, grafting and crosslinking are among the major irreversible methods of chemically modifying polymer properties. Grafting is a method by which a monomer or a polymer is covalently attached onto another polymer chain. Crosslinking on the other hand is the joining of two or more molecules or molecular chains through a covalent bond by another monomer or polymer called crosslinking agent. Grafting of polymers to protein chains results in a new class of proteinaceous biomaterials comprising natural and synthetic building blocks that are important in diverse fields of application including drug delivery, biotechnology, nanotechnology and nanobiotechnology ${ }^{187,188}$ Materials produced as a result of covalent attachment of synthetic polymers to proteins have the potential to synergistically merge the advantages of proteins and synthetic polymers. The hybrid materials may keep the chemical structure, diverse functionalities, stability, solubility, biocompatibility and biocompostability of proteins while keeping the stability and processability of synthetic polymers. ${ }^{189,190}$

The graft polymerization of styrene on soy protein isolate, ${ }^{191} 2$ hydroxyethyl methacrylate on soy protein, ${ }^{192}$ poly(ethylene glycol) on soy protein, ${ }^{193}$ polycaprolactone on zein, ${ }^{194}$ waterborne polyurethane on soy protein, ${ }^{195}$ poly(ethylene oxide) diglycidyl ether on wheat protein, ${ }^{196}$ methyl methacrylate, ethyl methacrylate and butyl methacrylate on camelina meal ${ }^{197}$ has been widely reported. Wu et al. ${ }^{194}$ reported that the grafting of polycaprolactone onto zein protein resulted in a dramatic flexibility improvement, while the strength remained constant. Moreover, the glass transition temperature and melting temperature were also shown to decrease due to the plasticizing effect of polycaprolactone on the protein. Kurniawan et al. ${ }^{196}$ also showed that the chemical modification of wheat protein based biopolymers with poly(ethylene oxide) diglycidyl ether resulted in the formation of a different network structure of the biopolymer with an improved flexibility, and improved mechanical performance.

Chemical crosslinking modification of protein with various agents to improve the mechanical, thermal and moisture resistance of the resulting biopolymers is another technique that has been widely studied..$^{160,161,196,198,199}$ Chemical crosslinking of proteins usually depends on the availability of particular chemicals that are capable of reacting with the specific kinds of functional groups that exist in proteins. The most extensively used chemical crosslinking agents of proteins include aldehydes (formaldehyde, glutaraldehyde, glyoxal, benzaldehyde), ${ }^{161,200,201}$ carbodiimide, maleic anhydride, hydroxysuccinimide, etc. ${ }^{202-204}$ Most of the studies show that crosslinking improved the tensile strength, tensile modulus, and moisture and solvent resistance, while the flexibility is reduced. ${ }^{160,161}$ In summary, protein-based plastics can be easily modified through plasticization; grafting or crosslinking due to the presence of several functional groups provides proteinbased plastics great promise in a wide range of applications. Further research into plasticizer/modification technique selection that combines the characteristics of the different protein feedstock with performance is necessary if protein based plastics are to achieve their full commercial potential.

\subsection{Cellulose acetate}

Cellulose is an abundant, renewable, and biodegradable natural polymer that constitutes the skeletal part of plants. It is a 
homogeneous polysaccharide formed by repeating connection of D-glucose building blocks (Fig. 10), with an average degree of polymerization of 1500 to 3000 depending on the source. ${ }^{205}$ Industrial materials are being developed from cellulose and its derivative over a broad range of application because of its abundance, environmental and biocompatibility benefits, relatively low cost and ease of modification. Cellulose by itself is poorly soluble in common solvents and is not melt processable as it decomposes before it undergoes melt flow. ${ }^{206}$ Nonetheless, the chemistry of cellulose opens the way to various chemical modifications, such as esterification and etherification give entry into a broad variety of products including coatings, base for photographic films, filters, pharmaceutics, fragrances, polymer additives, membranes and building materials. ${ }^{207-209}$ The most industrially relevant and oldest biodegradable cellulose ester derivative is cellulose acetate. ${ }^{208}$ Cellulose acetate and mixed cellulose esters, such as cellulose diacetate, cellulose triacetate, cellulose acetate propionate, and cellulose acetate butyrate, are all commercially available materials. ${ }^{208}$ These thermoplastic materials are usually synthesized through esterification of cellulose, ${ }^{\mathbf{2 1 0}}$ where other substituent groups replace the hydroxyl groups of cellulose (Fig. 10). For instance, cellulose acetate is the product of esterification reaction between cellulose and acetic anhydride in the presence of sulfuric acid catalyst to form fully acetylated cellulose triacetate, followed by partial hydrolysis to remove acid catalyst and produce a degree of substitution in the polymer that yields the desired working properties. ${ }^{211}$ Other methods of cellulose ester synthesis, such as transesterification of cellulose with vinyl esters under catalysis, are reported in the literature recently. ${ }^{212}$

Raw materials such as cotton, recycled paper, wood cellulose, and sugarcane are used in making cellulose ester biopolymers in powder form. ${ }^{210}$ Cellulose ester powders combined with plasticizers and additives are extruded to produce various grades of commercial cellulosic plastics in pelletized form. Of great interest as potential biodegradable plastics are also long chain aliphatic acid esters of cellulose. ${ }^{206,213}$ These cellulose esters are
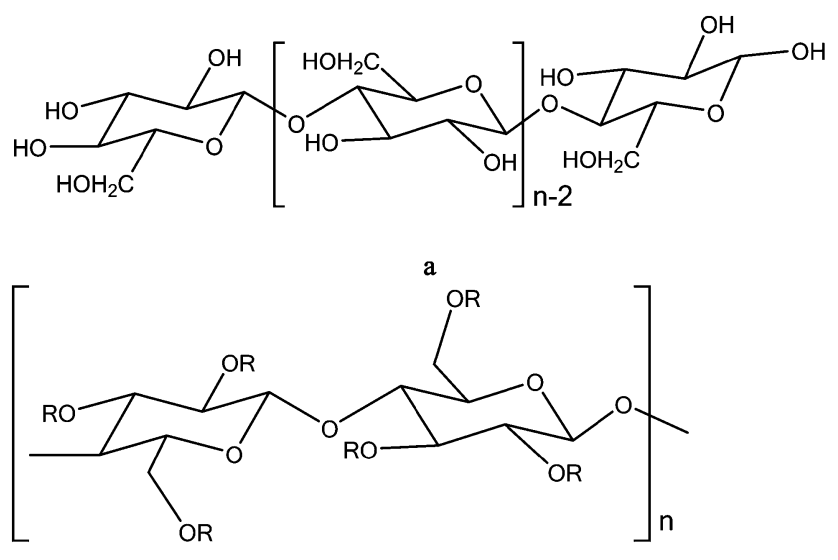

b

Fig. 10 Schematic representation of the molecular structure of (a) cellulose ( $n$ degree of polymerization) and (b) cellulose ester (R-functional group for each type of cellulose ester). characterized by stiffness, moderate heat resistance, high moisture vapor transmission, grease resistance, clarity and appearance, and moderate impact resistance. ${ }^{206}$ The presence of polar functional groups in the cellulose acetate chain offers an additional advantage of affinity to solvents including plasticizers and lithium ions for the development of polymer electrolytes. ${ }^{\mathbf{2 1 4}}$ Nevertheless, owing to the high viscosity and elevated glass transition temperature, cellulose acetate derivatives themselves are not processable as a thermoplastic. ${ }^{209}$ In an effort to modify its properties and facilitate processing, cellulose acetate is modified through plasticization by various aliphatic and aromatic esters, ${ }^{215,216}$ chemically modified through grafting onto the polysaccharide backbone, and modification by forming polymer blends. ${ }^{208,216,217}$

3.5.1. Plasticizers for cellulose acetate. The thermal and rheological properties of polymers are crucial factors for thermoplastic processability of polymers. A broad processing window without thermal degradation of polymer is necessary to adjust the required rheological behavior of the polymers. Cellulose acetate is characterized by high glass transition and melting temperatures. As such the addition of processing aids such as plasticizers is required to improve its rheological behavior or thermal processability in the polymer melt. The most common plasticizers for cellulose acetate plastics reported in the literature include diethyl phthalate, dimethyl phthalate, triphenyl phosphate, ethylhexyl adipate, flexol, triacetin, glycerol triacetate, triethylene, glycol dipropionate and a wide variety of other plasticizers. ${ }^{\mathbf{2 1 8 - 2 2 0}}$

Zepnik et al. ${ }^{221}$ have recently studied the effect of plasticizer type and concentration on cellulose acetates using benzoate, acetates, phosphate and citrates based plasticizers. An increase in plasticizer concentration resulted in significant broadening of the thermoplastic processing window due to a strong decrease in glass transition temperature. It was thus possible to tune the rheology, melt strength and thermoplastic processing cellulose acetate by changing the plasticizer concentration. On the other hand molecular size, chemical structure, and solubility variation of plasticizers were shown to influence its compatibility, and ultimately the efficacy. It is generally agreed that plasticizers that have higher thermodynamic compatibility with the base polymer cause better plasticization than those with limited compatibility. The selection of an efficient plasticizer for cellulose esters was suggested by Fridman and Sorokina $^{219}$ who developed a set of criteria for efficient plasticization of cellulose acetate. An efficient plasticizer should take into account the compatibility of components, temperature durability and mechanical properties during processing and service time of the final polymer.

The efficiency of a plasticizer depends also on the loading concentration. Fig. 11 and 12 show the effect of one of the common cellulose acetate plasticizer (diethyl phthalate) concentration on the thermal and mechanical properties of cellulose acetate (drawn from tabulated data reported by Fridman and Sorokina ${ }^{219}$ ). As the plasticizer concentration increases, a reduction in glass transition temperature was observed and hence a significantly lower processing temperature is needed, while a substantial thermal stability drop 
resulted in the cellulose ester plastic (Fig. 11). On the other hand, an increase in plasticizer concentration resulted in an increment of impact strength (Fig. 12) and elongation at break accompanied by a drop in tensile strength. Similar trend of cellulose acetate stiffness and toughness properties was observed by Mohanty et al. ${ }^{\mathbf{2 1 0}}$ upon increasing triethyl citrate plasticizer concentration. In summary, the type of the plasticizer and optimum plasticizer concentration are key parameters to reduce the processing temperature without compromising the stability and other performances of the plastic.

While cellulose acetate or its degradation products are safe, some of its common plasticizers such as phthalates, triacetin, glycerin, polyethylene glycol are associated with high toxicity, relatively high diffusion and water solubility. ${ }^{222,223}$ For example, deterioration of cellulose acetate as a result of migration or evaporation of plasticizers, reaction of plasticizers with other chemicals in their surroundings to form other products has been documented in the literature. ${ }^{218}$ As a result of such deterioration, not only unsafe plasticizers and plasticizer reaction products are released to the environment, but materials developed from cellulose ester became prone to cracking, warping, discoloration, exudation, shrinkage and powdering as they age. ${ }^{224}$

To mitigate these safety issues in addition to awareness of green technology and government legislations, several mitigation efforts are being conducted. These efforts include the development of safe, more stable and more compatible, biobased, and functional plasticizers. Sugar based plasticizers, such as sorbitan, ${ }^{\mathbf{2 1 6}, 225}$ polyoxyethylene sorbitan monopalmitate, ${ }^{225}$ polyoxyethylene sorbitan monostearate, ${ }^{216}$ are also reported. The use of an ionic liquid plasticizer synthesized from choline chloride and urea, such as deep eutectic solvent (DES), has been recently reported as a safe and novel plasticizer of cellulose acetate. ${ }^{226}$ These plasticizers have the high solvating potential of crystalline cellulose acetate, and are less expensive, non-toxic and biodegradable in addition to their large electronegativity and delocalization of charge that enables them to positively influence ionic conductivity of cellulose ester. ${ }^{226,227}$ Other ionic solvent cellulose ester plasticizers reported in the literature include 1-allyl-3-methylimidazolium chloride, ${ }^{228}$ and other ionic liquids based on methylimidazolium and methylpyridinium cores with allyl-, ethyl-, or butyl-side chains. ${ }^{229}$

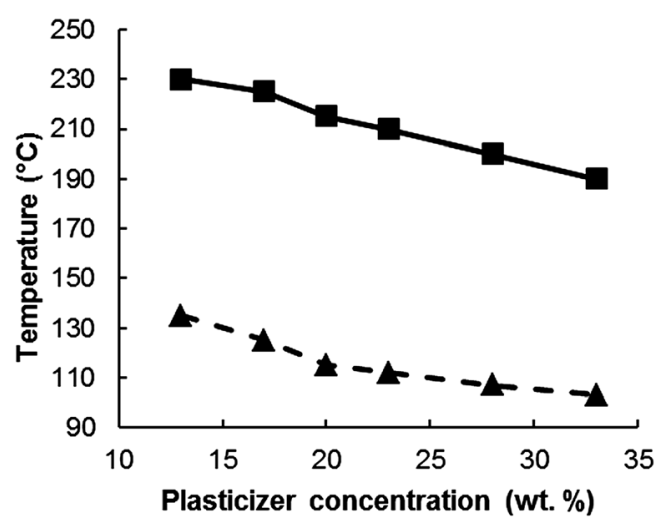

Fig. 11 Influence of diethyl phthalate concentration on $T_{\mathrm{g}}(\boldsymbol{\Delta})$ and processing temp ( $\boldsymbol{\square})$ based on the data from Fridman and Sorokina. ${ }^{219}$

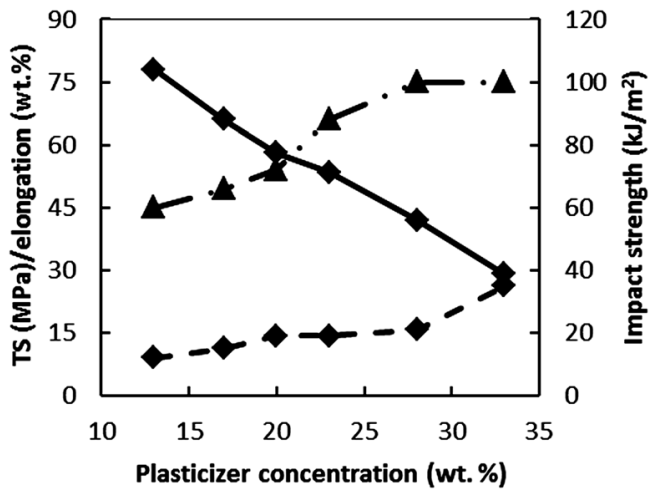

Fig. 12 Influence of diethyl phthalate concentration on impact strength $(\boldsymbol{\Delta})$, elongation ( $\mathbf{\square}$ ) and tensile strength (TS) ( $\bullet$ ) based on the data from Fridman and Sorokina. ${ }^{212}$

3.5.2. Other techniques of improving performance of cellulose acetate. Chemical modification of cellulose acetate through grafting and crosslinking with other polymers is the other widely reported strategy for improving the performance of cellulose acetate. ${ }^{208,217,230} \mathrm{Graft}$ copolymerization of polymers generally offers an attractive and versatile means of imparting a variety of functional groups to a polymer. ${ }^{\mathbf{1 8 5}}$ Cellulose acetate grafting is a process aimed at the introduction of branches of synthetic polymers along the main polysaccharide chain to confer specific additional properties to the former without modifying its intrinsic characteristics. ${ }^{231}$ Grafting offers the opportunity to combine the best properties of two or more polymers in one physical unit. Moreover, by varying parameters such as the degree of polymerization, polydispersities of the main chain and the side chains, graft density, and the distribution of the grafts, a more polymeric material with more valuable properties may result. ${ }^{217}$ Grafting of cellulose acetate with other polymers such as poly(lactic acid), ${ }^{\mathbf{2 3 2 , 2 3 3}}$ poly(methyl methacrylate), ${ }^{231,234}$ poly(hydroxybutyrate-co-valerate), ${ }^{235}$ caprolactone, ${ }^{32}$ polystyrene, ${ }^{236}$ poly(ethylene glycol) and poly(hydroxybutyrate) $^{237}$ with new and improved performance features including better conductivity, thermal stability, and other marked advantages with better control and property tuning capability has been reported in the literature.

\section{Concluding remarks}

The rapid technological development of bio-based plastics, such as PLA, polyhydroxyalkanoates, (PHA), bio-based epoxy resin and bio-based $\mathrm{PE}$, has yet to be translated into significant market impact, primarily due to high production cost and performance limitations. Plasticizers are important additives and performance enhancers of polymers. As such they can augment the processability of most of these bio-based plastics, and constitute a significant opportunity and at the same time barrier in the applications of bio-based plastics in various fields of applications. Moreover, the performance, safety, biodegradability, economics and functional utilization of bio-based plastics are strongly dependent on the performance of the incorporated plasticizers. This review highlights that selective 
use of a plasticizer at an optimum concentration allows controlling the balance between the processability, strength, modulus, toughness and other important mechanical properties of plastics. Such a selection is usually conducted based on reasons for application of plasticizer, mechanism of plasticizer action, interaction and effect of the plasticizer on other additives besides the biopolymer, concentration range depending on the application.

In addition to the sanction of some common plasticizers (e.g. phthalates) for various applications, due to environmental and health concern as a result of migration and leaching during aging or use of plastics, newer concerns are emerging with regard to the effect of plasticizers in maintaining the renewability and biodegradability of bio-based plastics. The development and utilization of bio-based plasticizers such as polyols, fatty acids and fatty acid derivatives, epoxidized soy oil, ester amides, citrates and ionic liquids, such as methylimidazolium chloride and deep eutectic solvent are widely reported to tackle such issues. These new forms of plasticizers offer new dimensions of plasticizer selection that provide additional functionality (e.g. electric conductivity by ionic liquids) to the bio-based plastics and some of the others provide high safety to be used even in edible food packaging applications. While most of the fundamental mechanism, physico-chemical interaction or rule of thumb in the selection of a suitable plasticizer were established for the synthetic plastics (mainly for PVC), there are hardly no newer theories/mechanisms for the relatively new bio-based plastics. As a result, most of the current plasticization investigations are conducted under the assumption that the mechanisms developed for PVC would also be valid for the bio-based plastics. A fundamental understanding of the plasticization mechanism of bio-based materials is essential, along with their similarity and difference with PVC, if they are to reach their full potential and success.

Besides the usual purpose of improving flexibility and processability, research is progressing in areas such as the search and modification of plasticizers that impart additional functions of flame retardancy, optical quality, electric conductivity or insulation, thermoxidative stability, chemical and temperature (high and low) resistance in demanding environments; reactive plasticizers that provide chemical integrity, gas and moisture impermeability improvement, provide or improve biodegradability and biocompatibility to the polymers are under investigation. The migration of some of the current bio-based plasticizers through either volatilization or mass transfer to a liquid or solid in contact poses another challenge. These and the other challenges led to the search for newer types of plasticizers and alternative methods of improving the processability and overall performance. Some of the alternative methods to plasticization include molecular orientation, physical and reactive blending, chemical crosslinking and grafting of the bio-based polymers with other polymers to tailor the ultimate product properties.

\section{Acknowledgements}

Tizazu H. Mekonnen, Paolo G. Mussone and David C. Bressler are grateful to PrioNet Canada, Alberta Prion Research Institute, Alberta Livestock and Meat Agency, and the Biorefining
Conversion Network at the University of Alberta for the financial support they received while they were researching and preparing this work.

\section{References}

1 R. U. Halden, Annu. Rev. Public Health, 2010, 31, 179-194.

2 M. M. Reddy, S. Vivekanandhan, M. Misra, S. K. Bhatia and A. Mohanty, Prog. Polym. Sci., 2013, DOI: 10.1016/ j.progpolymsci.2013.05.006.

3 B. Gervet, The use of crude oil in plastic making contributes to global warming, Lulea University of Technology, Sweden, 2007.

4 M. McCoy, Chem. Eng. News, 1998, 76, 15-18.

5 L. Shen, E. Worrell and M. Patel, Biofuels, Bioprod. Biorefin., 2010, 4, 25-40.

6 M. M. Reddy, M. Misra and A. K. Mohanty, Chem. Eng. Prog., 2012, 108, 37-42.

7 USDA Agriculture, ed. USDA, http://www.biocom.iastate. edu/workshop/2012workshop/presentations/pruszko.pdf, Washington, DC., 2008, accessed 21 May 2013.

8 R. Mathers, J. Polym. Sci., Part A: Polym. Chem., 2012, 50, 1-15.

9 M. Rahman and C. Brazel, Prog. Polym. Sci., 2004, 29, 12231248.

10 I. Lemer, Plasticizers to reach \$8 billion by 2004 Look Smart, Ltd, http://www.findarticles.com/cf_dls/m0FVP/ 9_258/65462810/p1/article.jhtml, accessed January 2010.

11 C. E. Wikes, J. W. Summers and C. A. Daniels, PVC handbook, Hanser Gardner Publications, Inc., 2005.

12 S. Cullen, Global Plasticizer Update, http://www. plasticsindustry.org/files/events/Stephen\%20Cullen_Tuesday. pdf, accessed 28 April 2013.

13 L. Sperling, Introduction To Physical Polymer Science, 4th edn, 2006, pp. 1-845.

14 P. De Groote, J. Devaux and P. Godard, J. Polym. Sci., Part B: Polym. Phys., 2002, 40, 2208-2218.

15 S. Varughese and D. Tripathy, J. Elastomers Plast., 1993, 25, 343-357.

16 E. Snejdrova and M. Dittrich, Pharmaceutical Applications of Plasticized Polymers, Recent Advances in Plasticizers, ed. Mohammad Luqman, Intech, 2012.

17 N. Ljungberg and B. Wesslen, Polymer, 2003, 44, 7679-7688. 18 D. Klee and H. Hocker, Biomedical Applications: Polymer Blends, 1999, 149, 1-57.

19 S. Tomic, M. Micic, S. Dobic, J. Filipovic and E. Suljovrujic, Radiat. Phys. Chem., 2010, 79, 643-649.

20 Y. Zhu, N. Shah, A. Malick, M. Infeld and J. McGinity, Int. J. Pharm., 2002, 241, 301-310.

21 Y. Li, C. Wang, G. Wang and Z. Qu, J. Wuhan Univ. Technol., Mater. Sci. Ed., 2008, 23, 100-104.

22 R. Sothornvit and J. M. Krochta, Innovations in Food Packaging, 2005, pp. 403-433.

23 E. H. Immergut and H. F. Mark, Principles of Plasticization, in Plasticization and Plasticizer Processes, American Chemical Society, Washington, DC, 1965. 
24 A. S. Wilson, Plasticisers: Principles and Practice, The Institute of Materials, London, UK, 1995.

25 A. Mohanty, M. Misra and L. Drzal, Abstracts of Papers of the American Chemical Society, 2002, vol. 223, pp. D70-D70.

26 P. Sarnacke and W. Stephen, Disposable Bioplastics: Consumer disposables agricultural films, a market opportunity study, United soybean board, Omni Tech International, Ltd., Midland, Michigan, 2008.

27 M. Vieira, M. da Silva, L. dos Santos and M. Beppu, Eur. Polym. J., 2011, 47, 254-263.

28 L. Lim, R. Auras and M. Rubino, Prog. Polym. Sci., 2008, 33, 820-852.

29 N. Gil, M. Saska and I. Negulescu, J. Appl. Polym. Sci., 2006, 102, 1366-1373.

30 O. Fenollar, D. Garcia, L. Sanchez, J. Lopez and R. Balart, Eur. Polym. J., 2009, 45, 2674-2684.

31 A. Stuart, M. McCallum, D. Fan, D. LeCaptain, C. Lee and D. Mohanty, Polym. Bull., 2010, 65, 589-598.

32 B. Videki, S. Klebert and B. Pukanszky, J. Polym. Sci., Part B: Polym. Phys., 2007, 45, 873-883.

33 L. Di Gioia, B. Cuq and S. Guilbert, Int. J. Biol. Macromol., 1999, 24, 341-350.

34 R. Sothornvit and J. Krochta, J. Food Eng., 2001, 50, 149-155.

35 B. P. Shtarkman and I. N. Razinskaya, Acta Polym., 1983, 34, $514-520$.

36 J. K. Sears and J. R. Darby, The Technology of Plasticizers, John Wiley \& Dpmd, New York, NY, 1982.

37 R. Drumright, P. Gruber and D. Henton, Adv. Biomater., 2000, 12, 1841-1846.

38 B. Gupta, N. Revagade and J. Hilborn, Prog. Polym. Sci., 2007, 32, 455-482.

$39 \mathrm{X} . \mathrm{Hu}, \mathrm{X}$. Jing, S. Sharma and A. Mudhoo, Handbook of Applied Biopolymer Technology: Synthesis, Degradation and Applications, 2011, pp. 291-310.

40 D. Garlotta, J. Polym. Environ., 2001, 9, 63-84.

41 A. Singha, V. Thakur, A. Singha and V. Thakur, Green Polymer Materials, 2012, pp. 1-14.

42 J. P. Penning, H. Dijkstra and A. J. Pennings, Polymer, 1993, 34, 942-951.

43 J. Lunt, Polym. Degrad. Stab., 1998, 59, 145-152.

44 P. Kurcok, A. Matuszowicz, Z. Jedlinski, H. Kricheldorf, P. Dubois and R. Jerome, Macromol. Rapid Commun., 1995, 16, 513-519.

45 H. Liu and J. Zhang, J. Polym. Sci., Part B: Polym. Phys., 2011, 49, 1051-1083.

46 L. Averous, M. Belgacem and A. Gandini, Monomers, Polym. Compos. Renewable Resour., 2008, 433-450.

47 A. Gupta and V. Kumar, Eur. Polym. J., 2007, 43, 4053-4074.

48 J. Huang, M. Lisowski, J. Runt, E. Hall, R. Kean, N. Buehler and J. Lin, Macromolecules, 1998, 31, 2593-2599.

49 R. Auras, B. Harte and S. Selke, Macromol. Biosci., 2004, 4, 835-864.

50 P. Zhao, Q. F. Wang, Q. Zhong, N. W. Zhang and J. Ren, J. Appl. Polym. Sci., 2010, 115, 2955-2961.

51 O. Martin and L. Averous, Polymer, 2001, 42, 6209-6219.

52 L. Averous and C. Fringant, Polym. Eng. Sci., 2001, 41, 727734.
53 S. Jacobsen and H. Fritz, Polym. Eng. Sci., 1999, 39, 13031310.

54 L. Labrecque, R. Kumar, V. Dave, R. Gross and S. McCarthy, J. Appl. Polym. Sci., 1997, 66, 1507-1513.

55 G. Maglio, A. Migliozzi and R. Palumbo, Polymer, 2003, 44, 369-375.

56 G. Maglio, M. Malinconico, A. Migliozzi and G. Groeninckx, Macromol. Chem. Phys., 2004, 205, 946-950.

57 G. Maglio, A. Migliozzi, R. Palumbo, B. Immirzi and M. Volpe, Macromol. Rapid Commun., 1999, 20, 236-238.

58 A. Gajria, V. Dave, R. Gross and S. McCarthy, Polymer, 1996, 37, 437-444.

59 E. Blumm and A. Owen, Polymer, 1995, 36, 4077-4081.

60 N. Ogata, T. Tatsushima, K. Nakane, K. Sasaki and T. Ogihara, J. Appl. Polym. Sci., 2002, 85, 1219-1226.

61 J. Park and S. Im, J. Polym. Sci., Part B: Polym. Phys., 2002, 40, 1931-1939.

62 F. Hassouna, J. Raquez, F. Addiego, P. Dubois, V. Toniazzo and D. Ruch, Eur. Polym. J., 2011, 47, 2134-2144.

63 N. Ljungberg and B. Wesslen, J. Appl. Polym. Sci., 2002, 86, 1227-1234.

64 F. Hassouna, J. Raquez, F. Addiego, V. Toniazzo, P. Dubois and D. Ruch, Eur. Polym. J., 2012, 48, 404-415.

65 Y. Xu and J. Qu, J. Appl. Polym. Sci., 2009, 112, 3185-3191.

66 B. Chen, T. Wu, Y. Chang and A. Chen, Chem. Eng. J., 2013, 215, 886-893.

67 Z. Ren, L. Dong and Y. Yang, J. Appl. Polym. Sci., 2006, 101, 1583-1590.

68 P. Suriyamongkol, R. Weselake, S. Narine, M. Moloney and S. Shah, Biotechnol. Adv., 2007, 25, 148-175.

69 S. Park, T. Kim, M. Kim, S. Lee and S. Lim, Biotechnol. Adv., 2012, 30, 1196-1206.

70 T. G. Volova, Polyhydroxyalkanoates plastic material of the 21st century, Nova science publishers, Inc., Hauppauge, New York, 2004.

71 K. Snell and O. Peoples, Biofuels, Bioprod. Biorefin., 2009, 3, 456-467.

72 G. Chen, Q. Wu, Y. Wang, Z. Zheng, X. Zhang, J. Tanaka, Y. Yu and Y. Tabata, Asbm6: Advanced Biomaterials Vi, 2005, 288-289, 437-440.

73 L. Yu, K. Dean and L. Li, Prog. Polym. Sci., 2006, 31, 576602.

74 B. Laycock, P. Halley, S. Pratt, A. Werker and P. Lant, Prog. Polym. Sci., 2013, 38, 536-583.

75 G. Chen and Q. Wu, Biomaterials, 2005, 26, 6565-6578.

76 A. Anderson and E. Dawes, Microbiol. Rev., 1990, 54, 450472.

77 H. Salehizadeh and M. Van Loosdrecht, Biotechnol. Adv., 2004, 22, 261-279.

78 I. Chodak, in Monomers, polymers and composites from renewable resources, Elsevier Ltd., Boston, US, 2008.

79 R. Baltieri, L. Mei and J. Bartoli, Macromol. Symp., 2003, 197, 33-44.

80 I. Chodak, in Degradable polymers, Kluwer Academic publishers, The Netherlands, 2002.

81 P. Ma, D. Hristova-Bogaerds, P. Lemstra, Y. Zhang and S. Wang, Macromol. Mater. Eng., 2012, 297, 402-410. 
82 M. Erceg, T. Kovacic and I. Klaric, Polym. Degrad. Stab., 2005, 90, 313-318.

83 J. Choi and W. Park, Polym. Test., 2004, 23, 455-460.

84 M. Correa, M. Branciforti, E. Pollet, J. Agnelli, P. Nascente and L. Averous, J. Polym. Environ., 2012, 20, 283-290.

85 S. Hong, H. Hsu and M. Ye, J. Therm. Anal. Calorim., 2013, 111, 1243-1250.

86 W. V. Srubar, Z. C. Wright, A. Tsui, A. T. Michel, S. L. Billington and C. W. Frank, Polym. Degrad. Stab., 2012, 97, 1922-1929.

87 M. A. Abdelwahab, A. Flynn, B. S. Chiou, S. Imam, W. Orts and E. Chiellini, Polym. Degrad. Stab., 2012, 97, 1822-1828.

88 M. O. Seydibeyoglu, M. Misra and A. Mohanty, Int. J. Plast. Technol., 2010, 14, 1-16.

89 I. Bibers, V. Tupureina, A. Dzene and M. Kalnins, Mech. Compos. Mater., 1999, 35, 357-364.

90 N. Yoshie, K. Nakasato, M. Fujiwara, K. Kasuya, H. Abe, Y. Doi and Y. Inoue, Polymer, 2000, 41, 3227-3234.

91 L. Miao, Z. Qiu, W. Yang and T. Ikehara, React. Funct. Polym., 2008, 68, 446-457.

92 T. Sadik, V. Massardier, F. Becquart and M. Taha, J. Appl. Polym. Sci., 2013, 127, 1148-1156.

93 C. Del Gaudio, L. Fioravanzo, M. Folin, F. Marchi, E. Ercolani and A. Bianco, J. Biomed. Mater. Res., Part B, 2012, 100, 1883-1898.

94 P. Ma, D. Hristova-Bogaerds, J. Goossens, A. Spoelstra, Y. Zhang and P. Lemstra, Eur. Polym. J., 2012, 48, 146-154.

95 R. Sadi, R. Kurusu, G. Fechine and N. Demarquette, J. Appl. Polym. Sci., 2012, 123, 3511-3519.

96 A. Tsui, Z. Wright and C. Frank, Annu. Rev. Chem. Biomol. Eng., 2013, 4, 143-170.

97 D. van Krevelen and $K$. te Nijenhuis, Thermal Decomposition, Processing Properties, in Properties of Polymers, Elsevier, Amsterdam, 2009.

98 M. Yamaguchi and K. Arakawa, Eur. Polym. J., 2006, 42, 1479-1486.

99 C. Bastioli, Starch/Staerke, 2001, 53, 351-355.

100 N. Cheetham and L. Tao, Carbohydr. Polym., 1998, 36, 277284.

101 J. Yu, J. Gao and T. Lin, J. Appl. Polym. Sci., 1996, 62, 14911494.

102 P. Russell, J. Cereal Sci., 1987, 6, 133-145.

103 P. J. Halley, R. W. Truss, M. G. Markotsis, C. Chaleat, M. Russo, A. L. Sargent, I. Tan and P. A. Sopade, Polymer Durability and Radiation Effects, 2008, vol. 978, pp. 287-300.

104 A. D. Sagar and E. W. Merrill, J. Appl. Polym. Sci., 1995, 58, 1647-1656.

105 F. Otey and R. Westhoff, Ind. Eng. Chem. Prod. Res. Dev., 1984, 23, 284-287.

106 E. Rudnik and E. Rudnik, Compostable Polymer Materials, 2008, pp. 11-36.

107 J. Yu, N. Wang and X. Ma, Starch/Staerke, 2005, 57, 494-504. 108 A. Taghizadeh and B. D. Favis, Carbohydr. Polym., 2013, 92, 1799-1808.

109 X. Ma, P. R. Chang and J. Yu, in Starch-Based Polymeric Materials and Nanocomposites, CRC Press, Florida, US, 2012.
110 P. Forssell, J. Mikkila, G. Moates and R. Parker, Carbohydr. Polym., 1997, 34, 275-282.

111 R. A. Talja, H. Helen, Y. H. Roos and K. Jouppila, Carbohydr. Polym., 2007, 67, 288-295.

112 Y. Zhang and J. H. Han, J. Food Sci., 2008, 73, E313-E324.

113 S. Raphaelides, G. Dimitreli, S. Exarhopoulos, G. Kokonidis and E. Tzani, Carbohydr. Polym., 2011, 83, 727-736.

114 F. Rodriguez-Gonzalez, B. Ramsay and B. Favis, Carbohydr. Polym., 2004, 58, 139-147.

115 P. Liu, L. Yu, X. Y. Wang, D. Li, L. Chen and X. X. Li, J. Cereal Sci., 2010, 51, 388-391.

116 R. A. de Graaf, A. P. Karman and L. Janssen, Starch/Staerke, 2003, 55, 80-86.

117 M. N. Abdorreza, L. H. Cheng and A. A. Karim, Food Hydrocolloids, 2011, 25, 56-60.

118 O. V. Lopez, C. J. Lecot, N. E. Zaritzky and M. A. Garcia, J. Food Eng., 2011, 105, 254-263.

119 Q. Q. Yan, H. X. Hou, P. Guo and H. Z. Dong, Carbohydr. Polym., 2012, 87, 707-712.

120 J. Ren, H. Y. Fu, T. B. Ren and W. Z. Yuan, Carbohydr. Polym., 2009, 77, 576-582.

121 R. A. Talja, H. Helen, Y. H. Roos and K. Jouppila, Carbohydr. Polym., 2008, 71, 269-276.

122 N. Laohakunjit and A. Noomhorm, Starch/Staerke, 2004, 56, 348-356.

123 X. Ma and J. Yu, J. Appl. Polym. Sci., 2004, 93, 1769-1773.

124 R. Shogren, C. Swanson and A. Thompson, Starch/Staerke, 1992, 44, 335-338.

125 X. Ma, J. Yu and F. Jin, Polym. Int., 2004, 53, 1780-1785.

126 J. Yang, J. Yu and X. Ma, Chin. Chem. Lett., 2006, 17, 133136.

127 J. Yang, J. Yu and X. Ma, Carbohydr. Polym., 2006, 63, 218223.

128 S. Flores, L. Fama, A. Rojas, S. Goyanes and L. Gerschenson, Food Res. Int., 2007, 40, 257-265.

129 N. Wang, X. Zhang, H. Liu and B. He, Carbohydr. Polym., 2009, 76, 482-484.

130 A. Sankri, A. Arhaliass, I. Dez, A. Gaumont, Y. Grohens, D. Lourdin, I. Pillin, A. Rolland-Sabate and E. Leroy, Carbohydr. Polym., 2010, 82, 256-263.

131 E. Leroy, P. Jacquet, G. Coativy, A. Reguerre and D. Lourdin, Carbohydr. Polym., 2012, 89, 955-963.

132 P. Kubisa, Prog. Polym. Sci., 2004, 29, 3-12.

133 A. L. Chaudhary, P. J. Torley, P. J. Halley, N. McCaffery and D. S. Chaudhary, Carbohydr. Polym., 2009, 78, 917-925.

134 A. L. Chaudhary, M. Miler, P. J. Torley, P. A. Sopade and P. J. Halley, Carbohydr. Polym., 2008, 74, 907-913.

135 A. Alissandratos, N. Baudendistel, S. L. Flitsch, B. Hauer and P. J. Halling, BMC Biotechnol., 2010, 10.

136 P. B. Zamudio-Flores, A. V. Torres, R. Salgado-Delgado and L. A. Bello-Perez, J. Appl. Polym. Sci., 2010, 115, 991-998.

137 B. Volkert, A. Lehmann, T. Greco and M. H. Nejad, Carbohydr. Polym., 2010, 79, 571-577.

138 N. Reddy and Y. Q. Yang, Biotechnol. Bioeng., 2009, 103, 1016-1022.

139 F. Xie, E. Pollet, P. J. Halley and L. Averous, Prog. Polym. Sci., 2013, DOI: 10.1016/j.progpolymsci.2013.05.002. 
140 Z. Liu, Y. Dong, H. Men, M. Jiang, J. Tong and J. Zhou, Carbohydr. Polym., 2012, 89, 473-477.

141 J. Zhou, J. Zhang, Y. Ma and J. Tong, Carbohydr. Polym., 2008, 74, 405-410.

142 R. Nakamura, A. Netravali, A. Morgan, M. Nyden and J. Gilman, Fire Mater., 2013, 37, 75-90.

143 V. Madison and J. Schellma, Biopolymers, 1972, 11, 10411076.

144 S. Swain, S. Biswal, P. Nanda and P. Nayak, J. Polym. Environ., 2004, 12, 35-42.

145 A. Gennadios, C. L. Weller, M. A. Hanna and G. W. Froning, J. Food Sci., 1996, 61, 585-589.

146 K. Dangaran, P. Tomasula, P. Qi, M. Embuscado and K. Huber, Edible Films and Coatings For Food Applications, 2009, pp. 25-56.

147 A. Elzoghby, W. El-Fotoh and N. Elgindy, J. Controlled Release, 2011, 153, 206-216.

148 S. Khosravi, P. Nordqvist, F. Khabbaz and M. Johansson, Ind. Crops Prod., 2011, 34, 1509-1515.

149 Z. Peles and M. Zilberman, Acta Biomater., 2012, 8, 209217.

150 H. Tian, J. Compos. Mater., 2012, 46, 427-435.

151 M. Santin and L. Ambrosio, Expert Rev. Med. Devices, 2008, 5, 349-358.

152 Y. Song, Q. Zheng and Q. Zhang, J. Cereal Sci., 2009, 50, 376-380.

153 S. Domenek, M. Morel, A. Redl and S. Guilbert, Macromol. Symp., 2003, 197, 181-191.

154 H. Yue, Y. Cui, P. Shuttleworth and J. Clark, Green Chem., 2012, 14, 2009-2016.

155 C. Verbeek and L. van den Berg, Macromol. Mater. Eng., 2010, 295, 10-21.

156 C. J. R. Verbeek and L. E. van den Berg, J. Polym. Environ., 2011, 19, 1-10.

157 A. Denis, N. Brambati, B. Dessauvages, S. Guedj, C. Ridoux, N. Meffre and C. Autier, Food Hydrocolloids, 2008, 22, 989994.

158 A. Ullah, T. Vasanthan, D. Bressler, A. L. Elias and J. P. Wu, Biomacromolecules, 2011, 12, 3826-3832.

159 A. Jerez, P. Partal, I. Martinez, C. Gallegos and A. Guerrero, J. Food Eng., 2007, 82, 608-617.

160 T. Mekonnen, P. Mussone, N. El-Daher, P. Choi and D. Bressler, Macromol. Mater. Eng., 2013, DOI: 10.1002/ mame.201200429.

161 N. El-Thaher, T. Mekonnen, P. Mussone, D. Bressler and P. Choi, Ind. Eng. Chem. Res., 2013, 52, 4987-4993.

162 B. Cuq, C. Aymard, J. Cuq and S. Guilbert, J. Food Sci., 1995, 60, 1369-1374.

163 H. Zheng, Z. Tan, Y. Zhan and J. Huang, J. Appl. Polym. Sci., 2003, 90, 3676-3682.

164 V. Hernandez-Izquierdo and J. Krochta, J. Food Sci., 2008, 73, R30-R39.

165 M. Pommet, A. Redl, S. Guilbert and M. Morel, J. Cereal Sci., 2005, 42, 81-91.

166 A. Ullah and J. Wu, Macromol. Mater. Eng., 2013, 298, 153162.

167 J. W. Lawton, Cereal Chem., 2004, 81, 1-5.
168 N. Reddy, L. H. Chen and Y. Q. Yang, Ind. Crops Prod., 2013, 43, 159-164.

169 X. Q. Mo and X. Z. Sun, J. Am. Oil Chem. Soc., 2002, 79, 197202.

170 O. Orliac, A. Rouilly, F. Silvestre and L. Rigal, Ind. Crops Prod., 2003, 18, 91-100.

171 N. Cao, X. Yang and Y. Fu, Food Hydrocolloids, 2009, 23, 729-735.

172 L. Yang and A. T. Paulson, Food Res. Int., 2000, 33, 563-570.

173 S. S. Sohail, B. W. Wang, M. A. S. Biswas and J. H. Oh, J. Food Sci., 2006, 71, C255-C259.

174 M. Wihodo and C. I. Moraru, J. Food Eng., 2013, 114, 292302.

175 W. Wu, N. Hettiarachchy and M. Qi, J. Am. Oil Chem. Soc., 1998, 75, 845-850.

176 M. Pommet, A. Redl, M. Morel and S. Guilbert, Polymer, 2003, 44, 115-122.

177 M. J. Fabra, A. Jimenez, L. Atares, P. Talens and A. Chiralt, Biomacromolecules, 2009, 10, 1500-1507.

178 T. H. Shellhammer and J. M. Krochta, J. Food Sci., 1997, 62, 390-394.

179 M. J. Fabra, P. Talens and A. Chiralt, Food Hydrocolloids, 2010, 24, 384-391.

180 H. Xu, Y. W. Chai and G. Y. Zhang, J. Agric. Food Chem., 2012, 60, 10075-10081.

181 Z. Ibragimo, A. Yulchiba, Y. V. Zelenev and K. U. Usmanov, Vysokomol. Soedin., Ser. A, 1973, 15, 1831-1838.

182 P. Tummala, W. J. Liu, L. T. Drzal, A. K. Mohanty and M. Misra, Ind. Eng. Chem. Res., 2006, 45, 74917496.

183 J. T. Kim and A. N. Netravali, Macromol. Mater. Eng., 2012, 297, 176-183.

184 X. S. Huang and A. N. Netravali, Biomacromolecules, 2006, 7, 2783-2789.

185 A. Bhattacharya and B. N. Misra, Prog. Polym. Sci., 2004, 29, 767-814.

186 A. Bhattacharya and P. Ray, in Polymer grafting and crosslinking, John Wiley \& Sons, Inc., Hoboken, New Jersey, 2009.

187 R. M. Broyer, G. N. Grover and H. D. Maynard, Chem. Commun., 2011, 47, 2212-2226.

188 Y. X. Hu, D. Samanta, S. S. Parelkar, S. W. Hong, Q. A. Wang, T. P. Russell and T. Emrick, Adv. Funct. Mater., 2010, 20, 3603-3612.

189 J. Shu, B. Panganiban and T. Xu, Annu. Rev. Phys. Chem., 2013, 64, 631-651.

190 N. Dube, A. D. Presley, J. Y. Shu and T. Xu, Macromol. Rapid Commun., 2011, 32, 344-353.

191 D. L. Xi, C. Yang, X. Y. Liu, M. Q. Chen, C. Sun and Y. L. Xu, J. Appl. Polym. Sci., 2005, 98, 1457-1461.

192 H. Zhou, P. Jiang, C. Yang, J. Q. Jiang, H. Y. Bai, M. Q. Chen and X. Y. Liu, Acta Polym. Sin., 2008, 424-429.

193 R. Snyders, K. I. Shingel, O. Zabeida, C. Roberge, M. P. Faure, L. Martinu and J. E. Klemberg-Sapieha, J. Biomed. Mater. Res., Part A, 2007, 83, 88-97.

194 Q. X. Wu, T. Yoshino, H. Sakabe, H. K. Zhang and S. Isobe, Polymer, 2003, 44, 3909-3919. 
195 H. F. Tian, Y. X. Wang, L. N. Zhang, C. Y. Quan and X. Z. Zhang, Ind. Crops Prod., 2010, 32, 13-20.

196 L. Kurniawan, G. G. Qiao and X. Q. Zhang, Biomacromolecules, 2007, 8, 2909-2915.

197 N. Reddy, E. Q. Jin, L. H. Chen, X. Jiang and Y. Q. Yang, J. Agric. Food Chem., 2012, 60, 4872-4879.

198 N. G. Wang, L. N. Zhang and J. M. Gu, J. Appl. Polym. Sci., 2005, 95, 465-473.

199 C. M. Vaz, L. A. de Graaf, R. L. Reis and A. M. Cunha, Polym. Degrad. Stab., 2003, 81, 65-74.

200 S. K. Park, D. H. Bae and N. S. Hettiarachchy, J. Am. Oil Chem. Soc., 2000, 77, 1223-1227.

201 C. Marquie, J. Agric. Food Chem., 2001, 49, 4676-4681.

202 V. Tropini, J. P. Lens, W. Mulder and F. Silvestre, Ind.Crops Prod., 2004, 20, 281-289.

203 V. Tropini, J. P. Lens, W. J. Mulder and F. Silvestre, Cereal Chem., 2000, 77, 333-338.

204 S. Kim, D. J. Sessa and J. W. Lawton, Ind. Crops Prod., 2004, 20, 291-300.

205 E. Malmstrom and A. Carlmark, Polym. Chem., 2012, 3, 1702-1713.

206 K. Edgar, C. Buchanan, J. Debenham, P. Rundquist, B. Seiler, M. Shelton and D. Tindall, Prog. Polym. Sci., 2001, 26, 1605-1688.

207 T. Heinze and K. Petzold, Monomers, Polym. Compos. Renewable Resour., 2008, 343-368.

208 R. Quintana, O. Persenaire, L. Bonnaud and P. Dubois, Polym. Chem., 2012, 3, 591-595.

209 P. Zugenmaier, Macromol. Symp., 2004, 208, 81-166.

210 A. K. Mohanty, A. Wibowo, M. Misra and L. T. Drzal, Polym. Eng. Sci., 2003, 43, 1151-1161.

211 H. L. La Nieve, in Handbook of Fiber Chemistry, 3rd edn, ed. M. Lewin, 2007, vol. 16, pp. 1-1030.

212 X. Cao, S. Sun, X. Peng, L. Zhong, R. Sun and D. Jiang, J. Agric. Food Chem., 2013, 61, 2489-2495.

213 N. Joly, R. Granet, P. Branland, B. Verneuil and P. Krausz, J. Appl. Polym. Sci., 2005, 97, 1266-1278.

214 S. Ramesh and S. C. Lu, J. Power Sources, 2008, 185, 1439-1443.

215 M. Yoshioka, N. Hagiwara and N. Shiraishi, Cellulose, 1999, 6, 193-212.

216 J. Amim, L. Blachechen and D. Petri, J. Therm. Anal. Calorim., 2012, 107, 1259-1265.

217 D. Roy, M. Semsarilar, J. Guthrie and S. Perrier, Chem. Soc. Rev., 2009, 38, 2046-2064.
218 M. Schilling, M. Bouchard, H. Khanjian, T. Learner, A. Phenix and R. Rivenc, Acc. Chem. Res., 2010, 43, 888-896. 219 O. Fridman and A. Sorokina, Polym. Sci., Ser. B, 2006, 48, 233-236.

220 G. Wypych, Handbook of Plasticizers, William Andrew Inc., New York, 2004.

221 S. Zepnik, S. Kabasci, H.-J. Radusch and T. Wodke, J. Mater. Sci. Eng. A, 2012, 2, 152-163.

222 A. Ghebremeskel, C. Vernavarapu and M. Lodaya, Int. J. Pharm., 2007, 328, 119-129.

223 A. Ghebremeskel, C. Vemavarapu and M. Lodaya, Pharm. Res., 2006, 23, 1928-1936.

224 J. Ballany, D. Littlejohn, R. A. Pethrick and A. Quye, Probing the factors that control degradation in museum collections of cellulose acetate artefacts. in Historic textiles, papers, and polymers in museums, American Chemical Society, Washington, DC, 2001.

225 J. Amim, Y. Kawano and D. F. S. Petri, Mater. Sci. Eng., C, 2009, 29, 420-425.

226 S. Ramesh, R. Shanti and E. Morris, Carbohydr. Polym., 2013, 91, 14-21.

227 H. R. Jhong, D. S. H. Wong, C. C. Wan, Y. Y. Wang and T. C. Wei, Electrochem. Commun., 2009, 11, 209-211.

228 S. Ramesh, R. Shanti and E. Morris, Carbohydr. Polym., 2012, 87, 2624-2629.

229 A. Pinkert, K. N. Marsh, S. S. Pang and M. P. Staiger, Chem. Rev., 2009, 109, 6712-6728.

230 G. Stiubianu, A. Nicolescu, A. Nistor, M. Cazacu, C. Varganici and B. Simionescu, Polym. Int., 2012, 61, 1115-1126.

231 E. Bianchi, A. Bonazza, E. Marsano and S. Russo, Carbohydr. Polym., 2000, 41, 47-53.

232 C. Yan, J. Zhang, Y. Lv, J. Yu, J. Wu, J. Zhang and J. He, Biomacromolecules, 2009, 10, 2013-2018.

233 Y. Teramoto and Y. Nishio, Biomacromolecules, 2004, 5, 407-414.

234 J. Zhong, X. Chai and S. Fu, Carbohydr. Polym., 2012, 87, 1869-1873.

235 C. Buchanan, S. Gedon, A. White and M. Wood, Macromolecules, 1992, 25, 7373-7381.

236 C. Biermann, J. Chung and R. Narayan, Macromolecules, 1987, 20, 954-957.

237 G. Cheng, T. Wang, Q. Zhao, X. Ma and L. Zhang, J. Appl. Polym. Sci., 2006, 100, 1471-1478. 